\title{
Private school effects in urban and rural India: Panel estimates at primary and secondary school ages
}

\author{
Abhijeet Singh* \\ University of Oxford
}

July 11, 2014

\begin{abstract}
I present the first value-added models of learning production in private and government schools in India using unique panel data from Andhra Pradesh state. I examine the heterogeneity in private school value-added across different subjects, urban and rural areas, medium of instruction, and across age groups. Further, I also estimate private school effects on children's self-efficacy and agency. In rural areas, I find a substantial positive effect (>0.5 SD) of private schools on English, no effect on mathematics and heterogeneous effects on Telugu for 8-10 year old students; at 15 years, there are modest effects $(<0.2$ $\mathrm{SD})$ on mathematics and Telugu receptive vocabulary. I find no evidence of a positive effect in urban areas or on psychosocial skills. Results on comparable test domains and age groups correspond closely with, and further extend, estimates from a parallel experimental evaluation.
\end{abstract}

${ }^{*}$ I am grateful to my supervisors, Stefan Dercon and Albert Park, and to Steve Bond, John Muellbauer and Francis Teal for their encouragement and guidance in this project. I am also grateful for very helpful feedback received from anonymous referees, Harold Alderman, Sonia Bhalotra, Jishnu Das, Marcel Fafchamps, James Fenske, Paul Glewwe, Doug Gollin, Zoe James, Asim Khwaja, Pushkar Maitra, Karthik Muralidharan, Caine Rolleston, Tristan Zajonc and seminar participants in Oxford, at the Indian Statistical Institute, the Delhi School of Economics and NEUDC 2013 (Harvard University). I thank the Young Lives Project for providing the data in this paper and supporting this study. Young Lives is core-funded by UK aid from the Department for International Development and co-funded from 2010 to 2014 by the Netherlands Ministry of Foreign Affairs. Comments are welcome at abhijeet.singh@economics.ox.ac.uk 
The share of private schools in total enrolment has risen substantially across both urban and rural areas in India in the past 15 years (Kingdon, 2007), now accounting for about 30\% of enrolment in rural areas (Pratham, 2013); students in these schools perform much better on average in test scores (Muralidharan and Kremer, 2008); and frequently it seems that private schools achieve this better performance even with much lower expenditure per pupil than government schools (Desai et al., 2008).

In this paper, I answer three questions using a unique longitudinal dataset collected by the Young Lives study in Andhra Pradesh state, which has tracked two cohorts of children through multiple rounds of data collection at household and school level between 2002 and 2011. First, I estimate value-added models (VAMs) of learning achievement to evaluate whether, and to what extent, the better test performance of children in private schools is attributable to schools. Second, I examine whether the impact of private schools on test scores is heterogeneous across different tests, different age groups, different languages of instruction and across urban and rural areas. Third, I attempt to assess if private schools have a differential impact on psychosocial ('non-cognitive') skills of children, specifically their self-efficacy and agency.

These questions are central to understanding the implications of the rise of private schools for the educational sector in India. Establishing whether the private school premium is causal, and whether it is heterogeneous, is essential for understanding whether the rapid proliferation of private schools can be expected to improve abysmally low learning levels in Indian schools and, if so, in which domains and by how much; this is also essential for understanding the likely implications for inequality in test scores in India, which is already among the highest in the world (Das and Zajonc, 2010). Finally, an assessment of the impact of private schools on psychosocial skills is relevant in light of a large interdisciplinary literature, including recent studies in economics, that documents their importance both in the production of learning skills and on later life outcomes (e.g. Bandura, 1982, 1993; Cunha and Heckman, 2008; Cunha et al., 2010).

In rural areas, where private schools account for about a quarter of the total enrolment in our data, I find that value-added in test scores for students in private schools is substantially greater in English compared to government school students, moderately greater in receptive vocabulary and no worse in Mathematics between 
the ages of 8 and 10 years; in Telugu, the local language, children in English-medium private schools do worse than government school students but children in Telugumedium private schools perform as well while still out-performing government school students in English. At the age of 15 years, children in private schools significantly outperform government school children in Mathematics and Telugu receptive vocabulary, although estimated effect sizes remain relatively modest and only about 20 to 40 per cent of the (unconditional) cross-sectional difference in test scores. In urban areas, I find no evidence of a causal private school effect on test scores.

Private school students display higher cross-sectional levels of agency and selfefficacy than government school students. However, these differences invariably disappear upon inclusion of socio-economic controls and lagged achievement; in short, I do not find any evidence of a causal private school effect on psychosocial skills.

This paper makes significant contributions to the literature on the impact of private schools in India. It is the first paper in this literature to use individual-level panel data to estimate value-added models of achievement; it is the only study to cover both primary and secondary school aged children across urban and rural areas; in comparison to previously published work (discussed in Section 2), the analysis makes use of considerably more detailed test measures and background information in each survey wave; and finally, it is the first study to look at differences in the psychosocial skills across private and government schools.

I attempt in this paper to also add to a recent and growing literature, mostly from studies in the United States, on the robustness and reliability of value-added approaches to modelling achievement production. In particular, the richness of the data allow me to test some of the assumptions implicit in value-added models and quantify the extent to which any violations may bias estimated private school effects in these data. Using the Raven's test from two periods ago as a proxy, I show that bias due to selection on ability does not appear to significant. I further show that controlling for lagged parental assessments of a child's academic performance and for parental aspirations with regard to a child's education does not alter the size or significance of estimated private school effects from value-added models. This indicates that dynamic sorting, which may be caused due to decision-makers having access to different or more detailed information about children than just 
their previous test scores, also does not seem to be a major source of bias in these estimates.

Furthermore, part of the data used in this paper are contemporaneous to data collected by Muralidharan and Sundararaman (2013a, MS hereafter) for children of the same age, in the same state and tested on partly the same domains of learning. The MS study offers experimental variation, induced through the randomized assignment of school vouchers in a representative set of communities in Andhra Pradesh, and thus offers an ideal comparison for results in this paper to assess the presence and extent of systematic bias that may still be present in value-added models. As I document, the pattern of causal effects reported here, on a comparable set of indicators for a comparable cohort of children, is very similar to the MS study; this is, to my knowledge, the first comparison of experimental and value-added estimates for the effect of selection into different schools in a developing country and the first such comparison using independently drawn samples in any setting. In addition to documenting similar results for one sample of children, I extend the results of MS substantially by presenting results on older children of secondary school age, on children in urban areas and on non-curricular test domains (receptive vocabulary) and psychosocial skills. The MS study is focused exclusively on the curricular outcomes of children in rural areas aged about 8 to 10 years at the time of testing.

These results have important implications. Combined with the significantly lower per-pupil expenditure in private schools, discussed in Section 2, this indicates that private schools are considerably more productive than government schools on average. The much better performance of private school students in English may plausibly contribute a significant labour market premium for these children in the future; recent evidence using nationally representative data from 2005 suggests an increase in hourly wages by 13 per cent for men who can speak a little English and up to 34 per cent for those who can speak it fluently (Azam et al., 2013). However, the insignificance or relatively modest size of the private school premium in most dimensions (with the exception of English) indicates that the spread of private schooling alone, without concomitant reforms across the education sector, will not lead to very appreciable improvements in the low levels of learning in Indian schools as measured by achievement in mathematics or the ability to read and write. 
The robust performance of value-added models, in a developing country setting with decidedly non-random selection across school types, may have methodological and practical relevance. While experimental evidence, preferably on representative samples and with minimal attrition, remains very desirable for measuring the causal effects of different educational inputs and interventions, such data are unlikely to be always available or always feasible to collect; results in this paper support the reliability of value-added estimates using panel data in these settings.

Results in this paper may resonate more broadly than merely Andhra Pradesh or the Indian context. Low-fee private schools have increased their share in enrolment across several developing countries; in many countries in Latin America, Asia and Africa, they also seem to outperform government schools in test scores (Jimenez et al., 1991; Alderman et al., 2001; Andrabi et al., 2011; Bold et al., 2011). Given the similarity in findings on several dimensions of schooling across South Asia and these different contexts, evidence from India may have relevance for these contexts as well. ${ }^{1}$ Similarly, the methodological question about the presence and extent of any bias in value-added models is also relevant across different contexts.

The rest of this paper is structured as follows: Section 2 presents the background and context of the schooling sector in India; Section 3 presents the data; Sections 4 and 5 present the empirical specifications and results from VAMs exploring whether the private school effect is causal and whether it is heterogeneous; Section 6 discusses additional concerns and robustness; Section 7 explores the impact of private schools on psychosocial skills; Section 8 concludes.

\footnotetext{
${ }^{1}$ For instance, the insignificant or modest gains from input-based measures seems to hold across South Asian and African contexts (see Kremer et al., 2013; McEwan, 2013; Glewwe et al., 2013) as do institutional issues of teacher absenteeism (Chaudhury et al., 2006), low rates of attainment (Glewwe and Kremer, 2006) and equal or greater productivity of contract or para teachers (Atherton and Kingdon, 2010; Duflo et al., 2012; Muralidharan and Sundararaman, 2013b). For example, comparing their results on an extra contract teacher in Kenya to those of Muralidharan and Sundararaman (2013b) from the state of Andhra Pradesh, Duflo, Dupas and Kremer (2012) note that "[Muralidharan and Sundararaman] find average test score gains very similar to those we observe, as well as reductions in civil-service teacher presence, suggesting that very similar forces may be at play in a different geographic and institutional context." (p. 24)

While this study cannot itself claim external validity beyond the state of Andhra Pradesh in India, it is plausible that the results have some relevance for other Indian states and perhaps more broadly.
} 


\section{Private and Government schools in India}

As noted previously, the share of the private sector in total enrolment especially at the primary level has expanded very rapidly and a large literature finds significant difference in the test scores of children in these schools when compared to government school students. It has also been shown that government school teachers, although better-paid and more qualified than private school teachers, are also much more likely to be absent and much less likely to be teaching when in school (see e.g.Desai et al. 2008; Kingdon 2007; Muralidharan and Kremer 2008).

Several studies have noted that per-pupil spending is considerably higher in government schools compared to private schools. Kingdon (1996) reports, using data on schools in Lucknow from 1990, that per-pupil expenditure in government schools was roughly double the per-pupil expenditure in private unaided schools. This ratio has since multiplied; Muralidharan and Sundararaman (2013a) report annual cost per-child of Rs. 8390 in government schools and Rs. 2324 in private schools in Andhra Pradesh. This difference in per-child spending is largely reflects much higher salaries for permanent civil service (government) teachers compared to private school teachers and has increased due to the much higher growth in government salaries. Kingdon (2010) discusses this issue at considerable length with an overview of evidence from the last two decades. She also notes that such differences must have increased considerably since the Sixth Pay Commission recommendations have near-doubled the average salaries of teachers in government schools.

Assessing the causal contribution of private schools to the learning outcomes of pupils is beset with serious problems of endogenous selection: there are systematic differences in observable characteristics of students in the two sectors and it is plausible that these may extend also to unobservable characteristics. Studies in the Indian context have adopted a series of econometric techniques to correct for this source of bias. ${ }^{2}$ The results in most cases seem to indicate that there is, in fact,

\footnotetext{
${ }^{2}$ Specifically, these studies have used the following approaches: controlling for observed background characteristics of children (Muralidharan and Kremer, 2008; Kingdon, 1996; French and Kingdon, 2010; Desai et al., 2008); running models with village fixed effects to isolate village-level confounders (French and Kingdon, 2010); with household fixed effects in cross-sectional data (French and Kingdon, 2010); with propensity score matching (Chudgar and Quin, 2012); and finally, through the use of Heckman selection models (Kingdon, 1996; Desai et al., 2008).
} 
a 'private school premium' in test scores which persists even when issues of selection have been dealt with as far as possible.

However, most studies previously available in the literature use only cross-sectional variation in test scores and a limited range of characteristics of children, schools and households to arrive at their estimates of the private school premium. An exception is French and Kingdon (2010) who create a village-level panel by looking at villages that were included in multiple rounds of Pratham's ASER survey between 2005 and 2007; this enables them to use village and year fixed effects. To my knowledge, with the exception of the contemporaneous MS study, no other study has been able to utilize individual-level panel variation in the data. The identification of private school effects in previous work in this literature, while perhaps the best that can be achieved given the data, remains vulnerable to several sources of endogeneity. ${ }^{3}$

The most convincing results on the effect of private schools in India are those from the MS study from the state of Andhra Pradesh, which is also the state in which the data used in this paper are collected. The MS study offered school vouchers through random assignment to children in the last year of pre-school (kindergarten) and Grade 1 for the entire duration of primary schooling up till Grade 5 which could be used to attend any private school in the village; this allows for clean identification of the magnitude of any private school effect. Results from the study indicate that children in private schools perform better in English and Hindi and no worse in Mathematics and Telugu even though up to $40 \%$ less instruction time is dedicated to these subjects in private schools than in government schools. The Young Lives data do not have Hindi test scores; however, for Mathematics, Telugu and English tests administered to a comparably aged cohort I document similar estimates of the private school effect.

\footnotetext{
${ }^{3}$ Ordinary Least Squares (OLS) regressions and propensity score matching estimators conditioning for limited background characteristics cross-sectionally are unlikely to have observed all relevant dimensions in which these children differ; within-village comparisons neglect the potential bias caused due to unobserved characteristics that lead households in the same village to making different choices regarding the enrolment of their children; household fixed effects remain vulnerable to differential enrolment within the household being related to either unobserved ability differences across children or, even more plausibly, to other unobserved differences in complementary investments; finally, variables used to control for selection in these studies using Heckman selection-correction estimators are unlikely to satisfy necessary exclusion restrictions. For example, Desai et al. (2008) use the presence of a private school in a village as a factor predicting selection into private schools but not test scores; this exclusion restriction is almost certainly untenable as villages that have a private school will differ from villages that do not. In fact such a pattern has clearly been documented by Pal (2010) using the PROBE dataset covering five Indian states.
} 


\section{Data}

\section{$2.1 \quad$ Sampling}

The data I use in this study were collected by the Young Lives study between 2002 and 2011 in the state of Andhra Pradesh. ${ }^{4}$ Andhra Pradesh is the fourth-largest state in India by area and had a population of over 84 million in 2011. It is divided into three regions - Coastal Andhra, Rayalaseema and Telangana - with distinct regional patterns in environment, soil and livelihood patterns. Administratively the state is divided into districts, which are further sub-divided into sub-districts (mandals) which are the primary sampling units within our sample. ${ }^{5}$

The Young Lives study in Andhra Pradesh has collected data on two cohorts of children: 1008 children born between January 1994 and June 1995, and 2011 children born between January 2001 and June 2002. Data was collected from children and their families using household visits in 2002, 2007 and 2009/10. The study also collected extensive data through visits to the schools of a randomly selected sub-sample of the younger cohort in 2011. Figure 1 presents graphically the timings of data collection and the age of the children at the time of the data collection. ${ }^{6}$ Attrition rates in the data have been kept very low - 1932 children (96 per cent) in the younger cohort and 976 children (97 per cent) in the older cohort are still in the sample in 2009. ${ }^{7}$ This has been achieved in part by following children whose households migrated from their original communities to their destination of migration.

\footnotetext{
${ }^{4}$ Young Lives is a longitudinal study of child poverty which follows two cohorts of children in four countries: Ethiopia, Andhra Pradesh state (India), Peru and Vietnam. For details, please visit www.younglives.org.uk

${ }^{5}$ The Young Lives sample is distributed across the three main regions and covers about 100 communities (villages or urban wards) across 20 sub-districts (mandals). A careful comparison with representative data for Andhra Pradesh shows that the data in the Young Lives sample contains similar variation across comparable measures: a detailed explanation of the sampling methodology and the comparison of the characteristics of the Young Lives sample with the DHS sample on a range of observed characteristics is reported in Kumra (2008). In 2014, the state of Andhra Pradesh was bifurcated with the creation of the new state of Telangana; throughout this paper, Andhra Pradesh refers to the undivided state.

${ }^{6}$ The interviews were usually carried out over a period of four to six months for the bulk of the sample. The timing of interviews given in Figure 1 corresponds to the end-period for the majority of the interviews which did not involve tracking children to different communities.

${ }^{7}$ Of the children who left the sample between 2002 and 2009, 36 children in the younger cohort and 5 in the older cohort had died between the rounds; 4 children in the younger cohort and 10 in the older cohort left as they did not want to be part of the survey anymore; the whereabouts of the rest could not be tracked. Most of this attrition occurred between the 2002 and 2006 rounds.
} 


\subsection{Data collected through household visits}

Extensive test data were collected from children in the sample in all rounds of the survey. The tests differed in their focus on which dimension of cognitive achievement they attempted to capture and how closely they related to the formal school curriculum in Andhra Pradesh; often, different tests were administered to children across rounds in order to ensure that they were appropriate for the age and the stage of education that the children were in. Box 1 lists the different test measures that are used in this paper. ${ }^{8}$

Box 1. Cognitive Tests in Young Lives

\begin{tabular}{|c|c|c|c|c|}
\hline COHORT & ROUND 1 (2002) & ROUND 2 (2007) & ROUND 3 (2010) & SCHOOL SURVEY (2011) \\
\hline $\begin{array}{l}\text { Older } \\
\text { Cohort }\end{array}$ & 8 years old & 12 years old & 15 years old & \\
\hline & Raven's test & $\begin{array}{l}\text { PPVT } \\
\text { Mathematics }\end{array}$ & $\begin{array}{l}\text { PPVT } \\
\text { Mathematics } \\
\text { Telugu (cloze) }\end{array}$ & [Not covered] \\
\hline $\begin{array}{l}\text { Younger } \\
\text { Cohort }\end{array}$ & 6-24 months old & 5 years old & 8 years old & 9 years old \\
\hline & & $\begin{array}{l}\text { PPVT } \\
\text { CDA Quantitative }\end{array}$ & $\begin{array}{l}\text { PPVT } \\
\text { Writing } \\
\text { Mathematics }\end{array}$ & $\begin{array}{l}\text { Mathematics } \\
\text { Telugu } \\
\text { English }\end{array}$ \\
\hline
\end{tabular}

PPVT refers to the Peabody Picture Vocabulary Test - III adapted for use in Telugu.

CDA refers to the Cognitive Development Assessment quantitative sub-scale.

Scores on all tests used in this paper, with the exception of the Raven's test, were generated using Item Response Theory (IRT) models. The use of IRT models is standard in education assessments and presents significant advantages: it allows for the accounting of difficulty of different items and, where the same test (or a sub-set) was administered over time, it allows for the computation of scores from the repeated tests on the same scale. ${ }^{9}$ Tests in which the same items were administered

Details of the attrition including characteristics of the individuals lost to attrition and implications for the representativeness of the sample are addressed at length in Outes-Leon and Dercon (2008).

${ }^{8}$ For precise details of the contents of the tests, as well as the validation for use in Andhra Pradesh, please consult Cueto et al. (2009), Cueto and Leon (2013) and the Young Lives questionnaires which are available at www.younglives.org.uk.

${ }^{9}$ For a detailed explanation of IRT models, please consult Das and Zajonc (2010) and Van der Linden and Hambleton (1997). I used the OpenIRT suite of commands in Stata written by Tristan 
were calibrated together which allows them to be put on the same scale. Test scores are normalized to have a mean of 0 and a standard deviation of $1 .^{10}$

The tests used in Young Lives are much more comprehensive in the domains of learning they capture and offer more variation than tests in most previous studies in the literature, which is a considerable strength of the data. In particular, the ASER data collected by Pratham and the India Human Development Survey 2005 (used in French and Kingdon 2010, Desai et. al. 2008 and Chudgar and Quin 2012) have only very basic test measures, on a more limited set of domains, which are not best-suited to capturing variation across the ability spectrum.

Data collection in 2002, 2007 and 2010 was at the households of the children. This data has particularly rich information about the socio-economic background of the children's households, parental expectations/aspirations for the children, and also detailed child-specific data. In the interest of clarity, I will explain individual variables being used in the estimation in the different empirical sections at the point at which they are being employed.

\subsection{Data collected from schools}

In 2011, the Young Lives study visited a random sub-set of schools being attended by children in the younger cohort. ${ }^{11}$ The sampling frame consisted of all the Younger Cohort (YC) children who were still enrolled in school in Round 3 (2009) and were

Zajonc to generate the maximum likelihood scores used in this papers. A core assumption of IRT models is that item parameters (e.g. difficulty) do not differ across sub-groups. This is not an assumption that is maintainable across different languages as difficulty levels may plausibly have changed during translation and therefore, in the case of the PPVT and the cloze test ('fill-in-theblanks') administered to the older cohort in 2009/10, I am constrained in only using the test scores of children who took the tests in Telugu; these account for over 90 per cent of the sample in each of the tests.

${ }^{10}$ The same items were administered in the PPVT in both rounds and a subset of items from the Round 3 math tests for the younger cohort were repeated in the school survey. In the case of tests in different rounds which were calibrated together, I have normalized scores by cohort to have a mean of zero in the first period in which the test is administered. Math scores for the older cohort in Rounds 2 and 3 cannot be linked to a common scale due to the unavailability of adequate link items administered in both rounds.

${ }^{11}$ It was not possible to visit all schools due to budgetary and logistical constraints. In total, 807 different schools were being attended by children in this cohort in 2009, 538 of those attended by only one Young Lives sample child; logistical and funding considerations limited the size of the sample targeted to 250 schools. 
going to school within Andhra Pradesh. ${ }^{12}$ The final sample includes 952 children across 247 schools. $^{13}$

The school-level survey was conducted between December 2010 and March 2011, i.e. in the school year immediately after the third wave of household-level data collection. The survey administered questionnaires to all Young Lives sample children in the school which included a battery of attitudinal items (used to generate measures of psychosocial skills). Sample children were administered tests in mathematics, Telugu and English.

\section{Empirical Framework}

Analysis in this paper, based on observational longitudinal data, will rely on valueadded models of achievement production. These models have been widely used in the literature on determinants of learning with several recent papers discussing their conceptual basis and the assumptions required for identification (see especially Todd and Wolpin, 2003, 2007; Rothstein, 2010; Andrabi et al., 2011 and Fiorini and Keane, 2014). In this section, I briefly present the empirical framework for the estimation of these models highlighting particularly their implicit assumptions and threats to identification in this particular instance.

\subsection{Education Production Functions}

The conceptual basis for value-added models is typically derived from a structural cumulative effects model. Following Todd and Wolpin (2003, 2007), it is possible to write the achievement production function in a general form:

\footnotetext{
${ }^{12}$ Sample children outside Andhra Pradesh were excluded from the frame as tracking them was unfeasible and because all questionnaires, tests and procedures were designed keeping the state education system in context; this left 1880 children in the sampling frame.

${ }^{13}$ The sampling was carried out within strata defined on whether the school was in an urban or a rural area, whether it was private or public and whether it was recognized or unrecognized, yielding a total of six strata. In each stratum, a pre-determined number of children were drawn randomly and all other Young Lives YC children in the school were covered as well. Where the child(ren) enrolled in a particular school had shifted schools since 2009, they were dropped from the school-based survey and were not followed to their new school unless the new school was also already in the sample. See James (2013) for a full description of the sampling procedure. Descriptive statistics and regressions for this sample are unweighted in this paper as appropriate survey weights are not archived in the Young Lives public use datasets.
} 


$$
y_{i s t}^{*}=F\left[X_{i}(t), S_{i}(t), \mu_{i s 0}, \epsilon_{i s t}\right]
$$

where the achievement $\left(y_{i s t}^{*}\right)$ of child $i$ in school $s$ at time $t$ is expressed as a function of the whole history of home-based inputs $X_{i}(t)$, school-based inputs $S_{i}(t)$, student endowments $\mu_{i s 0}$ (such as ability), and a time-varying error term $\epsilon_{i s t}$. While useful for conceptualizing the production technology for achievement, direct estimation of Eq (1) is not typically possible because the whole history of home and school inputs, as well as individual-specific endowments, are not observed by the researcher.

Equation (1) is typically linearized, as in the following equation provided by Andrabi, Das, Khwaja and Zajonc (2011):

$$
y_{i t}^{*}=\alpha_{1}^{\prime} \cdot x_{i t}+\alpha_{2}^{\prime} \cdot x_{i, t-1}+\ldots+\alpha_{t}^{\prime} \cdot x_{i 1}+\sum_{s=1}^{s=t} \theta_{t+1-s} \mu_{i s}
$$

where $x_{i t}$ is a vector of inputs for child $i$ at time $t, y_{i t}^{*}$ is true achievement at time $\mathrm{t}$ measured without error, and summed $\mu_{i s}$ are cumulative productivity shocks.

Adding and subtracting $\beta y_{i, t-1}^{*}$ to Equation (1) and assuming that coefficients decline geometrically yields the lagged value-added model:

$$
y_{i t}^{*}=\alpha_{1}^{\prime} \cdot x_{i t}+\beta y_{i, t-1}^{*}+\mu_{i t}
$$

Equation (3) is known as the lagged or dynamic OLS (DOLS) VAM. The lagged test score in the above specification is expected to capture the contribution of all previous inputs and any past unobservable endowments and shocks. This is believed to be a significant improvement over a contemporaneous specification, which links current test scores to only current inputs.

Implicitly, however, the specification remains vulnerable to bias from multiple sources, in addition to relying on strong assumptions of geometric decay and linearity as assumed earlier. First, conditioning on the lagged test score introduces the risk of bias due to measurement error which would attenuate the estimate of the persistence parameter $(\beta)$ but could also bias the input coefficients $(\alpha)$ in unknown direction. 
Secondly, the lagged test score can act as a summary statistic for mental ability only if enters through a one-time process or endowment. However, if talented children also learn faster, i.e. fixed ability has effects at every age, then $\beta$ will be upwardly biased (due to positive correlation with ability) and input coefficients may be as well. As Todd and Wolpin (2003, p. F21) discuss, the model then requires two sufficient statistics for identification - the lagged test score and mental ability at baseline: since mental ability may be correlated with the input vector $\mathbf{x}$, and will certainly be correlated with lagged achievement, its omission may substantially bias estimated coefficients.

The interpretation of the coefficients $\alpha$ depends crucially on what the included inputs in $\mathbf{x}$ are. If the input vector includes all contemporaneous inputs then the coefficients in the $\alpha$ vector can be interpreted as technology parameters i.e. the ceteris paribus effect of changing one input while keeping all other inputs fixed. This parameter, as Todd and Wolpin (2003) point out, is conceptually different from the parameter identified by randomized field experiments and natural experiments: the latter typically identify a total policy effect which captures the effect of changing the relevant input and allowing all other inputs to respond (i.e the total derivative with respect to $x$ ). In general, the two types of coefficients do not need to agree.

This issue is more generally relevant in the interpretation of results from value-added models. For example, the literature on teacher effectiveness typically estimates teacher effects by regressing current achievement on lagged achievement, a vector of contemporaneous (often fixed) child characteristics and a vector of teacher dummy variables, coefficients on which are interpreted as teacher value-added. As Todd and Wolpin (2003, p.F27-F28) point out, since these regressions typically do not control for other inputs that could be adjusted in response to teacher quality after the teacher assignment is known (for example, home inputs such as extra tutoring which could compensate for poor teacher quality), they typically identify policy effects and not technological parameters. ${ }^{14}$ This distinction will be important in the context of this paper both for interpreting the parameters estimated here and for their comparison to the results from the MS experimental study.

\footnotetext{
${ }^{14}$ This difference is independent of any concerns of endogeneity that may arise from some inputs being omitted; for example, these issues of interpretation would apply equally even if the relevant included inputs were randomly assigned.
} 


\subsection{Are value-added models reliable for the estimation of policy effects?}

The primary aim of this paper is to assess if the causal contribution of private schools to learning is significantly greater than the contribution of government schools. This parameter, the differential value-added of private schools, is a policy effect and not the ceteris paribus effect of private schooling. In this, my objective is most similar to the literature on identifying teacher and school effectiveness using value-added models. ${ }^{15}$

As noted in the previous sub-section, the consistency of estimates from value-added models relies on strong assumptions. It is therefore useful to assess the reliability of value-added models for the identification of treatment effects using results from recent studies. Guarino, Reckase and Wooldridge (forthcoming) assess the reliability of different value-added models for recovering teacher effects using simulated data with a variety of non-random assignment structures. Specifically, they assess the reliability of six different value-added estimators - a Dynamic OLS specification (as in equation 3), Arellano-Bond panel data estimators, pooled OLS on the gain score, an average residual approach, random effects on the gain score and fixed effects on the gain score - to different combinations of mechanisms to assign students to classrooms and teachers. They report that the DOLS model "was, by far, the most robust estimator across scenarios." (p.30) and that the "main strength of this estimator lies in the fact that, by including prior achievement on the right-hand side, it controls either directly or indirectly for grouping and assignment mechanisms". ${ }^{16}$ Related to our previous discussion of whether VAMs identify technology parameters or policy effects, they state that the DOLS estimator, as typically used to estimate teacher effects i.e. not controlling for all home or other inputs, may be thought of as a regression-based version of a dynamic treatment effects estimator (p. 31); it is in this sense that VAMs will be used in this paper.

The Guarino, Reckase and Wooldridge results are based on simulated data. Their relatively positive results mirror patterns in studies that compare effect sizes based

\footnotetext{
${ }^{15}$ For example, if private schooling results in positive behavioural changes (e.g. an increase in student effort) which result in better test performance, the parameter of interest here should not be estimated conditional on student effort.

${ }^{16}$ References to specific page numbers refer to the Working Paper version of the paper, Guarino et al. (2012), circulated as an IZA Discussion Paper.
} 
on VAMs to quasi-experimental and experimental results in a variety of contexts. Andrabi et. al. (2011) document, while analyzing the effectiveness of private schools in Pakistan (a setting very similar to the one in this paper), that biases from measurement error and unobserved heterogeneity are countervailing, and aggregate bias on the private school coefficient does not seem to be significant. ${ }^{17}$ Muralidharan and Sundararaman (2013b), in a paper on rural government schools in India, similarly document identical experimental and VA estimates of the effectiveness of contract teachers. ${ }^{18}$

Similar results are also emerging from a growing literature in the US: Deming et. al. (forthcoming) compare the effects of a school choice lottery in the US and find no significant differences between experimental estimates of school effects based on the school lottery and estimates from a value-added model that controls for previous test scores; Kane and Staiger (2008) and Kane et al. (2013), analyzing results from different experiments that assigned children randomly across classrooms, similarly report that teacher effect estimates that controlled for prior student test scores yielded unbiased predictions of test scores after randomization; Chetty et al. (forthcoming) find no evidence of bias when comparing estimates of teacher effectiveness using a value-added approach to estimates using previously unobserved parent characteristics and a quasi-experimental research design based on changes in teaching staff; and Angrist et al. (2013) also show how their estimates of Charter school estimates are identical when estimated on the same sample of children using lottery outcomes and separately using observational data (including baseline scores).

Finally, note that my aim in this paper is different from the teacher effectiveness literature in one important respect - namely, I am not attempting to recover a teacher or school-specific fixed effect. Much of the criticism surrounding VAMs has been regarding how individual teacher rankings may be substantially misclassified.

\footnotetext{
${ }^{17}$ Specifically, they report: "Despite ignoring measurement error and unobserved heterogeneity, the lagged value-added model estimated by OLS gives similar results for the private school effect as our more data intensive dynamic panel methods, although persistence remains overstated. The relative success of the lagged value-added model can be explained by the countervailing heterogeneity and measurement error biases on $\beta$ (their persistence parameter) and because lagged achievement can also act as a partial proxy for omitted heterogeneity in learning."

${ }^{18}$ Specifically, they show that a reduction in the pupil-teacher ratio has an equivalent impact whether it was caused due to the provision of an additional regular teacher or an experimentallyassigned contract teacher. Combined with additional results presented in their paper, that contract teachers and regular teachers had the same impact on test scores per year, this indicates that VA estimates of the impact of regular teachers were unbiased.
} 
For example, Guarino, Reckase and Wooldridge report that even though the DOLS recovers teacher effects reliably on average in most settings, there is considerable scope for the misclassification of individual teachers, thus leading them to caution against their use for high-stakes assessments of individual teachers. This is however, less of a concern for the purposes of this paper since I am not attempting to recover individual school level estimates but only the average difference in value-added between private and government schools. ${ }^{19}$

\subsection{Estimated specifications}

This paper uses a DOLS value-added model as the main specification in the analysis. The estimated specifications are similar across these samples but differ in some details due to different data availability. The core specification used for the estimation in the case of the 8-year old sample is as follows:

$$
\begin{aligned}
Y_{i t}= & \alpha+\beta_{1} \cdot \text { Private }_{i t}+\beta_{2} . \text { site }_{i} \\
& +\beta_{3} \cdot X_{i, t} \\
& +\beta_{4} \cdot Y_{i t-1} \\
& +\beta_{5} \cdot \text { timeuse }_{i t}+\epsilon_{i t}
\end{aligned}
$$

where Private $_{i t}$ is an indicator variable equaling 1 if the child is enrolled in a private school in 2009/10, with enrolment in a government school as the base category; site $_{i}$ is a vector of sentinel site (mandal) fixed effects; $X$ is a vector of background characteristics that includes caste dummies and wealth index, maternal and paternal years of schooling, household size, the sex of the child and whether he/she is the first-born child; $Y_{i, t-1}$ is the lagged test score; timeuse $_{i t}$ is the number of hours spent on a typical day in various activities - specifically, I control for the time use on caring for others, domestic tasks, studying outside of school time (including extra tuition),

\footnotetext{
${ }^{19}$ The other key distinction between the literature on teacher effectiveness in the U.S. and this paper is that there are no stakes attached (e.g. performance-based retention or financial rewards related to VA estimates) to the estimates, nor is any such policy move imminent or anticipated. For a discussion of how the addition of financial stakes may compromise the quality of information in VA estimates due to manipulation by teachers or schools, see Neal (2013).
} 
tasks on the family farm or other family business, time spent in school, time spent in play or general leisure, and paid work outside of the household (time sleeping is the omitted category).

The estimation includes controls sequentially as in Equations 4-7 and therefore the interpretation of $\beta_{1}$, the parameter of interest, changes with the inclusion of further controls. Equation (4) measures the unconditional cross-sectional difference in test scores within-community between students from private schools and government schools; Equation (5) presents a contemporaneous specification of the value-added model which controls additionally for a vector of background characteristics; Equation (6) is the Dynamic OLS specification of the lagged VAM; Equation (7) additionally includes time use.

Following the interpretation of Guarino, Reckase and Wooldridge (2012), $\beta_{1}$ in equations 4-6 can be thought of as a treatment effect, with the sequential addition of controls bolstering the reliability of estimates. Interpretation of equation (7) is not as clear immediately. In adding a full vector of time use categories, I follow the lead of Fiorini and Keane (2014) who similarly include a vector of time use categories in studying skill formation. However, while the inclusion of a vector of time use inputs carries potential advantages, it also presents challenges for interpretation and identification.

Time spent in different activities, such as studying, is clearly an input into the production of academic achievement, the omission of which could lead to bias in the estimation of the differential value-added by private schools. For example if, as is consistent with our data, students who go to private school studied longer after school and worked less on domestic tasks, then any differences in academic achievement caused by this differential allocation would be captured in coefficient $\beta_{1}$ in equation (6). This is not a problem for the identification of a treatment effect if the differences in time allocation were a result of private school attendance caused, for example, by private schools assigning more homework; in that case, differential time use is merely the channel through which private school effects are realized and these should not be controlled for. If, however, differential time use is a result of unobserved student background characteristics (e.g. parental motivation) then its omission will bias the resulting estimate of $\beta_{1}$ in Equation (6); that this may be a plausible scenario is indicated by the results of the MS study who document 
that time studying at home did not adjust upwards for lottery-winners who went to private schools. Given these issues surrounding the inclusion of time use inputs, I present estimates of $\beta_{1}$ both from equation (6) and equation (7). ${ }^{20}$ The inclusion of time use inputs is expected to provide lower-bound estimates of the treatment effect of private schools since it effectively assumes that the type of school does not affect time allocation patterns; conversely, omission of the time use vector provides an upper bound impact. ${ }^{21}$

In the 15-year sample, specifications are identical to the 8-year olds with one exception. Since about a fifth of the sample is no longer enrolled in school, I also include a dummy variable for not being enrolled in school in $2009 / 10 .{ }^{22}$ In the 9 -year old sample (2011), time use data was not collected and I use the time use as reported at 8 years (2010) as proxies for time allocation in $2011 .^{23}$

In the 8-year sample, I use scores from the maths test and the PPVT as outcome variables. I use the 2007 score on the quantitative section of the Cognitive Development Assessment as the lagged score for math and the 2007 score on the PPVT as

\footnotetext{
${ }^{20}$ The inclusion of time allocation patterns in value-added models also implicitly imposes a further restriction, namely that current productivity shocks do not result in (or, more generally, are correlated with) a change in time allocation. This is a strong assumption but one that is commonly made in the literature for example in Fiorini and Keane (2014) but also implicitly in Todd and Wolpin (2007) where they include the HOME score which includes various home investments such as the frequency of reading to a child and conducting various activities with the child; in both cases, the restriction that current productivity shocks do not affect child time use or parental time investments is assumed.

${ }^{21}$ This is not an assertion that can be made in general; for example, a priori it is entirely possible that parents compensate for lower quality government schools by making children study more at home, in which case the inclusion of time use inputs would bias upwards the total policy effect of private schools. It is made in this specific instance because of a noticeable pattern in the data where children in private schools spend significantly more time studying and because the MS study does not find differences in time spent studying at home for lottery-winners: if parents were indeed compensating for private school attendance by making children study more after school, we should have seen time studying at home to reduce significantly for the lottery-winners who attended private schools.

${ }^{22}$ The identifying assumption for the differential value-added is still one of conditional exogeneity, namely that conditional on covariates and lagged achievement assignment across type of school (including being not enrolled) is no longer correlated with the error term.

${ }^{23}$ Note that if both $T U_{t}$ and $T U_{t-1}$ were observed and included in the estimation, any significant effects of $T U_{t-1}$ would indicate that the structural assumptions underlying the lagged value-added model are violated. If only $T U_{t-1}$ is included, given that it is expected to proxy for current time use, the significance of lagged time use does not provide any clear evidence of such violation.

Using lagged time use to proxy for current time use implicitly imposes a strong assumption that agents do not re-optimize time use patterns upon the realization of current period shocks; it is, however, implied in the restriction of current time allocation being independent of the error term which is made in going from Equation (6) to Equation (7).
} 
the lagged measure for the PPVT in 2009/10. In the 9-year old sample, I have three test measures: a maths test (which had common items with the test administered in 2010), a test of Telugu competence and a test on English language competence. ${ }^{24} \mathrm{I}$ use the maths test in 2010 as the lagged measure for 2011 math test and the PPVT (administered in Telugu) as the lag for the Telugu test. Since a test in English was administered for the first time in 2011, I use the PPVT receptive vocabulary test score as the lagged achievement measure for English. In the 15-year old sample, I use PPVT, maths and Telugu as the outcome variables. ${ }^{25}$

In the main body of the paper, I only report results from Equations (6) and (7) but results in detail at each step are presented in Appendix tables A1 to A3 for rural areas. In all regressions in this paper, I cluster standard errors at the sub-district (mandal) level. ${ }^{26}$

\section{Results}

Descriptive statistics about the background characteristics of children in the younger and older cohort, disaggregated by the type of school in which they are enrolled, are provided in Tables 1 and 2. In both rural and urban areas, there are significant differences in the observable characteristics of children in government and private schools: children in private schools are likely to be from richer households with more educated parents and are much more likely to be male and first-born children. The share of private school enrolment varies across cohorts and across urban and rural

\footnotetext{
${ }^{24}$ At this point, children in the younger cohort were aged about 9-10 years which is exactly analogous to the age of the children in the MS study four years after their experimental intervention offering scholarships. Furthermore, they test the children on all of the three dimensions (Math, Telugu and English) in which test scores are available to us. Therefore results on this sub-sample are the most comparable to their experimental estimates.

${ }^{25}$ There is a difference in the period between the lagged assessment and the outcome assessment across the three age samples which makes the estimates across the samples incomparable as the dosage of treatment is different. This is addressed more fully in Section 5.

${ }^{26}$ Sub-districts, used for generating site fixed effects and for clustering standard errors, are taken as the first sub-district that the child was observed in (i.e. in 2002). For a subset of children whose households had moved out of the initial communities, but were tracked to their new location for the data collection, this is not the same as the sub-district they were observed in 2010 . The reason for this choice is that the locations of the migrated children in not available in the public-use Young Lives dataset other than a new category to indicate that children had migrated. Results are unchanged when restricted to the children whose households are still in the same communities as originally surveyed in 2002 .
} 
areas. Furthermore, whereas nearly all children in the younger cohort are enrolled in school, by the age of 15 about 22 per cent of children in this sample have dropped out of schooling.

Table 3 presents the raw magnitudes of the test score gaps between children in private and government schools across the three samples and across urban and rural areas. $^{27}$

In Table 4, I present the coefficient on the private school dummy from Equation (7), which includes all available controls, separately for rural areas, in all three samples. In rural areas (Panel A), at the age of 8 , there is a significant private school premium of about $0.13 \mathrm{SD}$ in PPVT which is about 35 per cent of the size of the within-community raw premium in test scores; there is no significant premium in maths test scores. At the age of 9 , there is no significant private school premium in maths but there is a very large private school premium in English of about 0.65 $\mathrm{SD}$; in Telugu, there appears to be a negative effect of attending private schools; this cohort is similar to the sample in MS and the pattern of incidence of private school effects is also similar. At the age of 15 years, there is a significant private school premium in all test scores (although not statistically significant for Telugu). The size of the premium in this cohort is relatively modest: about 0.15 SD for PPVT and the Telugu cloze test and about 0.2 SD for the math test; in each case, this is between 20-40 per cent of the raw baseline difference.

In urban areas, as is evident from Panel B, I do not find any statistically significant evidence of a private school premium in either cohort. While this could potentially be due to relatively small sample sizes in urban areas, this does not seem to be the case in practice: in the 15-year old sample, the coefficient itself is very close to zero; and the problem of low sample size is not as severe a problem for the 8-year-old sample as it has twice the number of observations. Certainly these results suggest that even if there is a private school premium in urban areas, which is not detected due to relatively small sample sizes, it is very unlikely to be large in magnitude.

As pointed out by previous research, as well as the MS study, the private school sector is very heterogeneous. A key aspect of heterogeneity is the medium of in-

\footnotetext{
${ }^{27}$ Since the 9 -year old sample has only 23 children in urban government schools, I do not report any results for children in urban areas for this sample. The very small sample size restricts me from making any reliable conclusions about results in this sample for urban areas.
} 
struction; while government schools teach all subjects in the local language, private schools may either use Telugu or English as the medium of instruction. In Table 5, I present results which re-estimate regressions for the 9-year old sample, distinguishing between English-medium and Telugu-medium private schools (with government schools as the base category). There is clear evidence of a private school premium in English across both Telugu and English medium private schools with the magnitude (about $0.8 \mathrm{SD}$ ) being expectedly greater in the latter but still substantial at about 0.5 SD even in Telugu-medium private schools. Importantly, the negative effect of private schools on Telugu seems to be concentrated entirely in the English-medium private schools and although substantial at $0.35 \mathrm{SD}$, it is still much smaller than the positive premium of $0.8 \mathrm{SD}$ in English. ${ }^{28}$ A further interesting pattern to note is that the coefficient on going to an English-medium private school, while not statistically significantly different from zero, is negative for mathematics while that for a Telugu-medium private school is positive; this also corresponds closely with patterns documented by $\mathrm{MS}^{29}$

While the pattern of incidence is identical, prima facie, there appears to be a major difference in the size of the private school effect in English; in their main results, relying on the random allocation of vouchers for identification, MS report a Local Average Treatment Effect (LATE) effect size of about 0.32 SD at 2.5 years (and even smaller at just above $0.2 \mathrm{SD}$ after four years) which is half the size of the effect I find.

This discrepancy in results could be caused due to various reasons. The first possible reason relates to the interpretation of the LATE parameter as estimated by the MS study. If the effect of private schooling is heterogeneous then, even in the absence of bias, treatment effects estimated will differ depending on the choice of IVs due to the change in the population of 'compliers' over whom the treatment effect is estimated. That this may partly be the case is highlighted by the results on heterogeneity by

\footnotetext{
${ }^{28}$ In the absence of estimates of labour market returns to English and Telugu, it is not clear how these trade-offs should be weighted (a point also made by MS). However, it is reasonable to assume that returns to English are significantly greater than local languages including Telugu - this is, for, example, the pattern documented by Munshi and Rosenzweig (2006) in Mumbai - and certainly seems to be the impression among parents, who view the additional English language proficiency provided by private schools as one of their biggest draws.

${ }^{29}$ The coefficients on English and Telugu-medium private schools are however always significantly different from each other, in Telugu at 5\% level of significance and in English and Mathematics at $10 \%$ level of significance.
} 
medium of instruction that MS present. In those regressions, where medium of school is instrumented using an interaction of receiving a voucher and the medium of instruction of the nearest private school, the treatment effect at 2.5 years is about 0.53 SD for English medium schools and 0.4 SD in Telugu-medium schools.

A further possibility could arise from the choice of test scores used in this study and in the MS study: whereas I use IRT scores in this paper, MS use a standardized raw score as their dependent variable. Since Item Response models allow items to differ in difficulty and other characteristics (e.g. guessing), they may change the contribution of each test item towards a composite test score and thereby the spread of the distribution. I reran the estimation using a (normalized) raw score as the dependent variable, following the procedure in MS. The main effect size I get is $0.32 \mathrm{SD}$ which is nearly identical to the estimate reported by MS.

That the choice of aggregation method should create such large changes in effect sizes raises questions about the reliability of the results. As a further check, to ensure that results reported here are meaningful, I calculated the proportion correctly answered on the English test for each different task administered and used them as separate dependent variables. The test administered seven distinct sets of tasks: linking numbers to words, linking pictures to words, linking pictures to sentences, completing a sentence by choosing a word from one of three options, answering questions based on reading a passage, open-ended cloze ('fill-in-the-blanks') items for sentence completion, and writing a sentence to describe a provided picture. Results are reported in Table 6 along with the mean proportion correctly answered by the government school students. As can be seen, the private school effect is significantly positive across all specifications indicating that the existence of a private school effect on English is not an artefact of the procedure undertaken to create a test score.

Moreover, expressing the private school effect as a percentage of the mean proportion correct in the government sector, the effects are larger on harder questions such as writing a complete sentence to describe a picture than on easier items such as linking numbers or pictures to words. The discrepancy between effect sizes could be a product of the implicit reweighting of items in the IRT scores and suggests that weighting all test questions equally (as the creation of raw scores does) understates the effect of private schools. 
The close correspondence between patterns in this paper and in the MS study is particularly striking. The nearly identical estimates indicate, in addition to a lack of bias in the VA estimates of the private school effect, that schools have not made material adjustments to their inputs as a result of the MS voucher and that there has also not been a large adaptation on the part of parents/households. MS document that lottery winners did not, in fact, change their time use patterns; further it seems unlikely that a one-off intervention applying only to one cohort of children (in kindergarten and Grade 1 at the start of the experiment) would lead schools to adapt their long-term production strategies. ${ }^{30}$

The results still have an unresolved interpretational issue. In the 8 and 15 year samples, the treatment effects estimated at best identify three-year effects of private school enrolment which, while still adequate to compare the government and private sectors within the samples, are not comparable to results for the 9-year old cohort (since the dosage there is one year). Under the assumptions of constant treatment effect for each year of schooling in each cohort of children, and geometric decay, this effect may be calculated if the true persistence parameter is known. Recovering the 'true' persistence parameter however, as Andrabi et. al. (2011) highlight in a similar application, requires substantially more stringent assumptions and richer data; in particular, the persistence parameter estimated in the dynamic OLS VAM is likely to biased. Andrabi et. al. (2011) document persistence parameters of between 0.2 and 0.5 i.e between one-fifth and one-half of learning persisting from year to year. ${ }^{31}$ Using these persistence parameter estimates, I can calculate the

\footnotetext{
${ }^{30}$ Put differently, the MS study differs from other voucher experiments in developing countries (see e.g.Hsieh and Urquiola, 2006 with data from Chile) since schools have not exhibited the full set of general equilibrium effects that might be expected if the voucher system were general, long-term and large in scope (as may indeed happen with the Right to Education Act in India). This, combined with the low evidence of household adaptation of inputs in response to the randomized receipt of vouchers, renders their results comparable with the VA estimates here.

For an example, using both experimental and panel-based variation from different settings, of how household adaptation to interventions can change policy effects see Das et al. (2013).

${ }^{31}$ The implied persistence coefficient in other South Asian studies is sometimes even lower. For example, the two interventions in Banerjee et al. (2007) show rapid fade-out and lead to implied persistence between .086 and 0.265 in math and below 0.06 for verbal abilities. Imperfect persistence has also been documented in various US datasets (e.g. Jacob et al., 2010,Rothstein, 2010 and Kane and Staiger, 2008) and seems to be a feature of education data more generally.

The MS study documents smaller effect sizes of private schooling on English after 4 years of private school attendance compared to 2.5 years, although not significantly so. Note also that our estimates at 9-years are actually one-year estimates while MS results are two-year effects; that the two sets of results happen to overlap almost exactly, is consistent with low persistence (but also with other possible explanations such as private school advantage in test scores being built at
} 
implied per-year effect from the three-year effects for the 8 and 15 year samples in Table 4. Assuming persistence of 0.2 per year implies, in the 8-year old sample, a per-year effect of about 0.1 SD ( $0.075 \mathrm{SD}$ if persistence is 0.5$)$ and at 15 years, a per-year effect size of $0.15 \mathrm{SD}$ in math and $0.12 \mathrm{SD}$ in $(\sim 0.1 \mathrm{SD}$ in math and 0.08 $\mathrm{SD}$ in PPVT if persistence is 0.5$)$. These effect sizes appear modest at best. ${ }^{32}$

\section{Additional concerns and robustness}

While previous studies on the robustness of VAMs have been encouraging, and indeed results in this paper on a comparable cohort and indicators conform closely with comparable experimental evidence, the possibility of bias in the estimates cannot be definitively ruled out; this may especially be a concern for indicators/cohorts for which external validation through the MS study is not available. From the perspective of estimating a treatment effect, a particularly important concern relates to potentially unobserved heterogeneity that may still bias the private school coefficient. Bias could also be caused due to dynamic sorting across school types. In this subsection, I evaluate the empirical relevance of these concerns.

\subsection{Unobserved differences in ability}

Lagged achievement suffices to account for ability differences between children only if these differences affect initial conditions and not learning at each point in time; as previously noted, in the latter case two sufficient statistics are required namely past achievement and the fixed ability measure. The richness of the Young Lives data allow me to investigate the severity of this bias directly for the older cohort of children, aged 15 in 2009.

In the first round of data collection in 2002, when the older cohort of children were 8 years old, the survey had administered the Raven's colored progressive matrices

school entry ages and then persisting). While this does not necessarily indicate zero persistence, it does highlight the pitfalls of using short-term teacher or school evaluations, whether randomized or non-experimental, to make assessments of long-term effects.

${ }^{32}$ This is not surprising given that even the three-year impacts appear quite modest: any persistence will cause one-year impacts to be less than the three-year impacts with the latter being upper-bound estimates of what one-year impacts may be. 
test which is a test of non-verbal reasoning which has widely been used as a proxy for intelligence or innate ability. ${ }^{33}$ In the Indian case, it has been used as such by Kingdon (1996) and Kingdon and Teal (2007, 2010). In the context of our application, it provides a possible way to test the structural assumptions of the dynamic VAM.

Given the assumptions of the VAM, if lagged achievement is a summary statistic for fixed ability and for all previous investments into cognitive ability, then the addition of the Raven's score from 2002 should not have any significant effect on achievement at $15(2009 / 10)$ when conditioning for achievement at age 12 (2007). Columns 1-3 in Table 7 show the effect of adding the Raven's score into the VAM used previously for the 15 year old sample. As can be seen, the Raven's score is significantly associated with learning at 15 , even when conditioning on achievement at 12. To the extent that the Raven's test is proxying for innate ability, or at least ability pre-determined at age 8, this pattern suggests that ability does not merely enter as a one-off endowment but has effects in every period. The second pattern to note, however, is that the private school coefficient has barely changed and is statistically indistinguishable from the result in Table 4. Given that the significant coefficient on the Raven's test score indicates a violation of the VAM assumption, this may appear surprising.

An explanation of this pattern can be discerned by looking at the partial correlations between private schooling, lagged achievement and the Raven's score. Specifically, I first regress private school attendance on the Raven's test and then add the background set of controls and lagged test scores from 2007 into the equation. ${ }^{34}$ As may be noted, while not controlling for background characteristics and lagged achievement, there is a weak positive association between the Raven's score and private school enrolment; upon inclusion of background characteristics and the lagged achievement measure(s), this association is no longer significant and with a coefficient very close to zero indicating that the lagged achievement and background controls do in fact proxy for any selection by ability.

\footnotetext{
${ }^{33}$ For instance, the Raven's test has been used as such by Boissiere et al. (1985), Alderman et al. (1996a,b), Glewwe (1996), Heady (2003) and Akresh et al. (2012). The Raven's test score is thought to be less affected by schooling than most other measures of cognitive ability although it has been shown to be affected by early childhood investments such as in nutrition.

${ }^{34}$ This regression is restricted to children who were observed in school in 2009/10.
} 
Given that the Raven's score at 8 is correlated with test scores at 12 , the possibility of a biased treatment effect remains since any bias in the coefficient on lagged achievement caused due to the omission of the Raven's score could transmit to the private school coefficient. The magnitude of any such bias on the private school coefficient depends multiplicatively on the partial correlation between private schooling and the lagged test score, and the partial correlation between the lagged test score and the ability measure (Raven's score). In this instance, both objects are quantitatively small - a 1 SD change in the Raven's test at 8 (which would be a very large change) has an effect of about .15 SD on the test score at age 12; in turn, a 1 SD change in the lagged test score has an effect of about $0.04-0.07$ on the probability of private school enrolment. Taken together, the modest partial correlations account for why the omission of the Raven's test does not significantly change the estimates of the private school effect.

Finally note that, given the positive asscoiation of the Raven's test with private school enrolment, these results imply that any bias from the omission of ability measures overstates the private school effect. It does not therefore invalidate the major conclusion of this paper that private school effects are at best modest in most dimensions of learning with the exception of English.

\subsection{Parental information, aspirations and dynamic sorting}

The robustness check above suggests that the lagged test score suffices to control for sorting by ability (at least as measured by the Raven's test) into private schools. However, a further related concern is that of dynamic tracking. Analogous to Rothstein's (2010) criticism (delivered in the context of tracking of students into different classrooms by headteachers), while VAMs may deliver unbiased estimates of the private school effect if selection was only on the variables controlled for and past achievement, it is plausible that parents observe more or different information on child achievement which is used as basis for selecting whether the child is enrolled into private or government schools. ${ }^{35}$

\footnotetext{
${ }^{35}$ Rothstein's (2010) key contribution was to develop falsification tests assessing whether future teacher assignments had an 'effect' on current test scores in a value-added framework; he finds, using data from North Carolina that they do, which indicates dynamic tracking not adequately controlled for in the value-added specification. Although later research has sometimes contested
} 
Parent's assessments of the child's academic performance may contain information other than that contained in test scores for at least two reasons. Parents may observe much more about their children than our survey measures can capture; and parental assessments may have significant measurement error of their own (if, for example, parents cannot reliably assess a child's actual progress i.e. how well the child should have done as opposed to actual achievement). Furthermore, it is always possible that parents differ in their degrees of aspirations for children and the preferences they have towards their education; if these preferences lead to a greater propensity to select into private schools (as they are perceived to be of higher quality) and also lead to higher home-based investment which is not captured in our range of controls or proxied by past achievement, then our estimate of the private school effect might be biased. The precise reason for (possible) divergence of parental assessments from achievement data on our test measures is not central to the issue; what is important is that selection on ability, if any, depends on the former (parental) measure and not the latter (test scores). If there is systematic divergence between the two, it is plausible that bias may still exist. ${ }^{36}$

I attempt to quantify the magnitude of bias that may exist due to these sources of bias by using unique proxies available in the Young Lives data for these sources of bias. In 2007 and 2009/10, in both cohorts, the household survey collected parents' assessments of how they thought the child (if enrolled at the time) was performing in school; the measure was collected on a five-point scale with 1 being "Excellent" and 5 being "Very bad". Furthermore, in 2007 the survey asked parents what they

the implications of these findings for the reliability of VAMs, e.g. by showing that the falsification test is not violated in Rothstein's data when correcting for small sample estimates (Kinsler, 2012) or by demonstrating that even otherwise, dynamic sorting and a rejection of the Rothstein test need not necessarily imply biased teacher estimates (Goldhaber and Chaplin, 2012), that is not my major concern here. Sorting which is not controlled for by the lagged achievement measures and controls could be a potential source of bias in my results; my focus is to assess, to the degree possible, the magnitude of such bias for my substantive findings about the relative effectiveness of private schools.

${ }^{36}$ I attempted to test directly the hypothesis that selection into private schools based on academic performance is driven exclusively by parental assessments of academic performance and not the objective test measures of performance. Specifically, I first regressed private schooling on the household controls and lagged test scores for each sample and note that lagged test measures are correlated with later private school attendance. I then add parental assessment of academic performance and parental aspirations for child education. I note that whereas these parental measures show correlations with private schooling that are statistically significant and quantitatively large in the expected direction, the coefficient on lagged test score is no longer significantly predictive of later private school enrolment. This provides suggestive evidence that the posited intuition about determinants of tracking is not misguided. Results are available on request. 
would desire as the highest level of education for their child, in the absence of any constraints. These measures appear meaningful: average test scores in mathematics seem to increase incrementally for each point of the parental assessment scale; similarly, parental aspirations about a child's education (reduced to a dummy variable for whether the parent would like the child to go to university) are positively associated in bivariate correlation with private school attendance. As a robustness check on this possible source of bias, I estimate the lagged VAMs on the all three age samples supplementing the specification with a vector of dummy variables for each point of the parental assessment scale (with "Excellent" as the omitted category) and a dummy variable for whether the parent desires the child to go to university. ${ }^{37}$

Results from this analysis are given for rural areas in Table 8; as can be seen, even though there is information in the parental assessments and their educational aspirations which is related to test scores, the coefficients on the private school dummy variable seem to be unchanged from the main estimates. ${ }^{38}$ I find no evidence of additional bias in the VAM specification estimated in the previous subsection.

\subsection{Dosage of treatment across samples and school migration}

The main results documented in Section 4 for children in the 8 and 15 year old samples rely on lagged achievement from three years ago (2006) and the type of school attended in 2009. This approach ignores any switching of schools between rounds which can contribute to bias.

The 2009 round of the survey collected retrospective school histories of children, eliciting their enrolment in various schools starting from the 2009/10 school year and going backwards. As James and Woodhead (2014) document, there is a considerable degre of mobility across schools in these data: about $16 \%$ of the younger cohort

\footnotetext{
${ }^{37}$ In 2007 , children in the 8-year cohort were aged between $4.5-6$ years and only about 44 per cent had joined formal schooling; for enrolled children parental assessment of performance at school was collected. Most other children were in preschools (including anganwadis) and the survey asked for the parent's assessment of child performance there. Together these two variables allow me to construct lagged measures of parental assesment for the 8-year old cohort.

${ }^{38}$ This is true for most coefficients in the regressions apart from the lagged achievement measures which decline in magnitude. This indicates that parents' assessments of child performance, although informative, do not seem to bias the estimates and probably reflect information similar to the lagged achievement measures.
} 
children have changed school at least once by the age of 8 years in 2009; in urban areas, about $13.5 \%$ of this move is across sectors while in rural areas about $58 \%$ of the move is across sectors, the bulk of which is a movement from government to private schools.

Table 9 presents the years of schooling in the private and government sectors in the three academic years $2007 / 8,2008 / 9$ and $2009 / 10$ by children in the sample. ${ }^{39}$ There is both migration across sectors and different doses of treatment depending on any years that the child may have been out of school in this period. My approach in dealing with these issues is limited by what is feasible by the data. As a first pass, I estimated a variant of the VA model presented in Section 4 where, instead of private school attendance in 2009/10, I include the years of schooling in private schools and government schools between 2007/8 and 2009/10 school years. Results are presented in Table 10. As may be noted, the qualitative results are not different from the results presented in Table $4 .{ }^{40}$

An alternative approach is to estimate the VAMs from Section 4 on only the subsample that has stayed in school for the entire period and not migrated across sectors. This subsample is similar to the sample that would have been obtained if, as in several other surveys, children were first surveyed in schools and then followed in

\footnotetext{
${ }^{39}$ In the 8-year old sample, I adopt a slightly different procedure in counting years in school in government and the private school sectors: whereas I treat enrolment in pre-primary grades ('kindergarten' classes) in private schools as being in school, I do not count enrolment in public preschools as such. This is due to to the way preschools are arranged in the two sectors: whereas kindergarten classes are frequently integrated in private primary schools and focus on learning, government preschools (anganwadis) are more akin to daycare centres without a clear focus on learning and in typically other surroundings than the school environment. For greater detail on the preschool to school transitions in the Young Lives data, please see Singh (2014) and Woodhead et al. (2009).

${ }^{40}$ The specification implicitly imposes a common coefficient on each year of private or government schooling regardless of the timing of the treatment: thus, for example, attending a private school in $2007 / 8$ or in $2009 / 10$ are taken to have the same effect on test scores in 2010 . This is a strong assumption that will be violated by any imperfect persistence of test scores which as discussed previously is very likely. It is hard to think however, why such decay will differentially affect private school students compared to government school students and thus our conclusions about the relative contribution of private vs. government schools should not be affected. Therefore I have chosen this specification both due to ease of presentation and interpretation and because sample sizes are adequate to make the relevant comparisons.

The most general specification possible is to include a dummy variable for being in private or government school in each year from 2007/8 to 2009/10 (inclusive) with out of school children as the base. However, the variation in schooling status from year-to-year (in terms of migrants either in/out of schooling or across schooling sectors) is not adequate to reliably estimate, for example, the effect of a year in private school in $2007 / 8$ vs. 2008/9.
} 
later rounds only conditional on still being enrolled there. ${ }^{41}$ Coefficients in rural areas are higher (although not significantly so) when the sample is restricted only to those who have stayed within the same sector. ${ }^{42}$ Results for rural areas are presented in Appendix table A.4.

The checks above seem somewhat reassuring that, whereas switching does complicate the estimation of private school effects, it does not alter our basic finding that private school effects along these dimensions are modest, if at all significant.

\subsection{Lag structure}

Finally, I estimate specifications which test for the possibility of a different lag stucture in the VAMs: specifically, I estimated the main regression specifications by including also lagged measures from time $t-2$ instead of just a single period lag and, separately, including a third-order polynomial of the lag (as in Deming et. al. forthcoming, Chetty et. al. forthcoming and Kane and Staiger 2008) instead of the lag only in levels; coefficients on the private school premium seem stable and unchanged. These results are available on request but have not been included in the paper.

\footnotetext{
${ }^{41}$ Although it should be noted that sample sizes reduce importantly, especially for the younger cohort, due to the exclusion of children who have been in school only for a part of the three academic years up until 2009/10.

${ }^{42}$ Migration across school sectors may be thought of as measurement error leading, if migration is ignorable, to attenuation bias which would cause coefficients to be biased towards zero. To the extent that there is selection into migration based on characteristics that also contribute to learning, it is reasonable to expect any such unobservables driving migration into private schools to be positively correlated with learning outcomes; for example James and Woodhead (2014) document through numerous qualitative interviews that migration is related to parental aspirations, incomes, voice and information. In this scenario, the difference in coefficients between the full sample and the restricted subsample in Table 8 overstates the effect of measurement error in the treatment variable.

The pattern noted above, of coefficients increasing only very modestly when restricting the sample to those who were in school for all three years compared to the full sample including all children, is consistent with low persistence; with a persistence of, say, 0.2 from year-to-year only $4 \%$ of the private school effect from 2007/8 will remain till the end of the 2009/10 school year, which would be consistent with the pattern of no distinguishable change in coefficients.
} 


\section{Do private schools have an impact on psychosocial skills?}

Recent literature within economics (Cunha and Heckman, 2008; Cunha et al., 2010) and an older literature in child psychology (e.g.Bandura, 1982, 1993) has stressed that psychosocial skills (sometimes called 'non-cognitive' skills) have a direct impact on the production of cognitive skills and on later life outcomes. As such, it seems useful to ask whether private schools have additional effects on these skills, apart from their effect on test scores. To my knowledge, this role has not been evaluated previously but may be important to assess in any evaluation of the total effect of private schools.

In the 2011 data collection, conducted in schools of a randomly selected subset of the younger cohort children, collected a battery of attitudinal items relating to their experience of schooling, their belief in their own abilities, and the extent to which they believe their academic outcomes are within their control. Of the items administered, I select statements related to two dimensions which are clearly identifiable as related to psychosocial skills given an older literature within child psychology. The first dimension is agency/locus of control which is a measure of the extent to which individuals feel in control of their future outcomes (see, e.g.,Findley and Cooper, 1983).The second dimension is self-efficacy which measures the extent to which individuals believe in their own abilities in particular domains (see Bandura 1993). ${ }^{43}$

The self-efficacy scale is defined using six statements and the agency/locus-of-control scale using four statements. Raw responses on the statements are provided in Panel A of Table 7, reducing the statements to whether or not a child agreed with a particular statement. As can be seen, on all statements private school students report more positive assessments although this difference is not always statistically significant. Panel B aggregates the statements into two indexes - as can be seen, whereas differences in the agency/locus-of-control index are not statistically significant, differences in self-efficacy are.

\footnotetext{
${ }^{43}$ These concepts are closely linked but are distinct from each other. See, in particular, the discussion in Ajzen (2002) on the difference between 'controllability' and self-efficacy and in Maddux and Gosselin (2002) about differences between self-efficacy and numerous related concepts.
} 
In order to assess if these differences may plausibly be contributed by private schools, I estimate the following specification:

$$
P_{i, 2011}=\alpha+\beta_{1} \text { Private }_{i, 2011}+\beta_{2} . \text { site }_{i}+\beta_{3} \cdot X_{i, 2010}+\beta_{4} \cdot Y_{i, 2007}+\epsilon_{i t}
$$

where $P_{i, 2011}$ is the relevant psychosocial outcome variable; site $e_{i}$ is a vector of site dummies; $X$ is a vector of background characteristics which includes dummy variables for being male and for different caste groups, maternal and paternal years of education and a wealth index for the household; $Y_{i, 2007}$ includes the mathematics and PPVT test scores from 2007; and $\epsilon_{i, t}$ is an idiosyncratic error term. As previously, I enter the right-hand-side variables sequentially. I have chosen to include test scores from 2007 (instead of more recent measures from 2010) because they predate school entry for most of the sample with the rest being in their first year of formal schooling. ${ }^{44}$

Results from the estimation for both indexes are presented in Table 8. As is evident, the cross-sectional difference in the indexes drops with the inclusion of background controls and lagged achievement and is statistically insignificant for both indexes. I do not find any evidence for a differential effect of private schools on these measures.

\section{Conclusion}

In this paper, I investigated the extent of test score gaps between students of private and government schools across several cognitive domains for children aged 8 years, 9 years and 15 years in rural and urban areas; I have tried to isolate the extent to which any gaps might be causal effects of private schools; and I have attempted to understand the sources of learning achievement at the school level.

\footnotetext{
${ }^{44}$ Unlike test scores, in which we expect progression annually, it is not obvious that psychosocial outcomes may also be expected to improve yearly even in good schools. If, say, some schools instill better motivation in children at the start of schooling and this is contained in their subsequent test performance (as is likely), then controlling for test scores after school entry will produce a downward biased estimate of the productivity of schools regarding these skills.

Identification in this case rests on an assumption of conditional exogeneity, when controlling for test scores.
} 
Raw differences in test scores between children in private and government schools are invariably substantial, statistically significant, and favour private school students. However, much of this variation seems to be a reflection of greater home investment and socio-economic background. Upon controlling for a wide ranging set of controls and prior achievement, for younger children I find evidence of substantially better performance only in English and a somewhat smaller effect on receptive vocabulary. For older children, I do find significant impacts of going to private schools on their scores in mathematics and Telugu; while these differences are consistently significant, they are relatively modest at about $0.2 \mathrm{SD}$ and only between 20-40 per cent of the average within-community difference in test scores. In urban areas, I find no evidence of a significant private school effect. I also do not find significant evidence of a causal private school effect (relative to public schools) on psychosocial skills.

The results have several implications of interest for policy-makers. Combined with previous work highlighting that the average cost per child in rural private schools is a fraction of of the average cost in the state schools, and that private schools dedicate less instructional time to Telugu and mathematics, they suggest strongly that private schools are considerably more productive than government schools. However, they also imply that the spread of private schools is unlikely to raise average achievement levels as measured by mathematics skills or functional literacy significantly; with the exception of English, I do not find any large and consistently positive 'private school effect'. To the extent that the first-order concern for education policy in India remains the abysmally low levels of achievement in general, rather than the inefficiencies in the delivery of education services, the spread of private schooling by itself is clearly not an adequate solution. ${ }^{45}$

The large and significant private school premium in English, provided without any trade-off in other subjects in the case of Telugu-medium private schools and only a modest trade-off in English-medium schools, could lead to a possibly large wage

\footnotetext{
${ }^{45}$ The dichotomy between the two objectives - raising overall achievement and reducing the perunit cost of achievement production - is partly artificial: it is, of course, possible (even desirable) for policy-makers to be concerned about both of these objectives. However, it needs to be acknowledged that the two objectives are distinct. Supportive evidence that the rapid rise in private schooling will only partially, if at all, address the problem of low achievemnt in Indian schools is also provided by the two major trends documented in the 2012 ASER Report(Pratham, 2013): while private schools have rapidly increased in their share of enrolment in rural areas between 2005 and 2012, achievement levels across states have either stayed flat (for example, in Andhra Pradesh) or in many states even declined.
} 
premium for private school students in the future. Combined with the selectivity on socio-economic background in the private sector, this premium provides possible grounds for concern that private schools hinder social mobility and facilitate the intergenerational persistence of socio-economic status.

This study also attempts to contribute methodologically to the literature. The close correspondence of the results with experimental estimates on a comparable sample from Muralidharan and Sundararaman (2013a), as well as other robustness checks reported in the paper, provide evidence of the robustness of value-added models as a mechanism for investigating causal differences in school effectiveness, which echoes a recent literature from the US and Pakistan. This is important since experiments may not be uniformly feasible across contexts and convincing natural experiments may not be available in many situations where evaluating a relevant policy question remains important. In the Indian context, it is additionally important to evaluate the robustness of VAMs since it is plausible that, if public schools do move towards a system of targeting learning outcomes instead of merely inputs (as advocated by, for example, Muralidharan 2013), then panel data on child learning outcomes would be available across the Indian public educational system. In such a scenario, it is likely that the use of VAMs will proliferate - it is worthwhile to know the extent to which such analytical exercises will be reliable and useful. 


\section{References}

Ajzen, I. (2002). Perceived behavioral control, self-efficacy, locus of control, and the theory of planned behavior. Journal of Applied Social Psychology, 32(4):665-683.

Akresh, R., Bagby, E., De Walque, D., and Kazianga, H. (2012). Child ability and household human capital investment decisions in Burkina Faso. Economic Development and Cultural Change, 61(1):157-186.

Alderman, H., Behrman, J. R., Ross, D. R., and Sabot, R. (1996a). Decomposing the gender gap in cognitive skills in a poor rural economy. Journal of Human Resources, 31(1):229-254.

Alderman, H., Behrman, J. R., Ross, D. R., and Sabot, R. (1996b). The returns to endogenous human capital in Pakistan's rural wage labour market. Oxford Bulletin of Economics and Statistics, 58(1):29-55.

Alderman, H., Orazem, P. F., and Paterno, E. M. (2001). School quality, school cost, and the public/private school choices of low-income households in Pakistan. Journal of Human Resources, 36(2):304-326.

Andrabi, T., Das, J., Khwaja, A. I., and Zajonc, T. (2011). Do value-added estimates add value? Accounting for learning dynamics. American Economic Journal: Applied Economics, 3(3):29-54.

Angrist, J. D., Pathak, P. A., and Walters, C. R. (2013). Explaining Charter School Effectiveness. American Economic Journal: Applied Economics, 5(4):1-27.

Atherton, P. and Kingdon, G. (2010). The relative effectiveness and costs of contract and regular teachers in India. Working Paper 15, Centre for the Study of African Economies (CSAE) University of Oxford.

Azam, M., Chin, A., and Prakash, N. (2013). The returns to English-language skills in India. Economic Development and Cultural Change, 61(2):335-367.

Bandura, A. (1982). Self-efficacy mechanism in human agency. American Psychologist, 37(2):122-147.

Bandura, A. (1993). Perceived self-efficacy in cognitive development and functioning. Educational Psychologist, 28(2):117-148. 
Banerjee, A. V., Cole, S., Duflo, E., and Linden, L. (2007). Remedying Education: Evidence from Two Randomized Experiments in India. The Quarterly Journal of Economics, 122(3):1235-1264.

Boissiere, M., Knight, J. B., and Sabot, R. H. (1985). Earnings, schooling, ability, and cognitive skills. The American Economic Review, 75(5):1016-1030.

Bold, T., Kimenyi, M., Mwabu, G., and Sandefur, J. (2011). The High Return to Private Schooling in a Low-income country. Working Paper 279, Center for Global Development, Washington, D.C.

Chaudhury, N., Hammer, J., Kremer, M., Muralidharan, K., and Rogers, F. H. (2006). Missing in action: teacher and health worker absence in developing countries. The Journal of Economic Perspectives, 20(1):91-116.

Chetty, R., Friedman, J. N., and Rockoff, J. E. (forthcoming). The long-term impacts of teachers: Teacher value-added and student outcomes in adulthood. The American Economic Review, forthcoming.

Chudgar, A. and Quin, E. (2012). Relationship between private schooling and achievement: Results from rural and urban India. Economics of Education Review, 31(4):376 - 390 .

Cueto, S. and Leon, J. (2013). Psychometric characteristics of cognitive development and achievement instruments in Round 3 of Young lives. Young Lives Technical Note 25, Young Lives, University of Oxford.

Cueto, S., Leon, J., Guerrero, G., and Muñoz, I. (2009). Psychometric characteristics of cognitive development and achievement instruments in Round 2 of Young Lives. Young Lives Technical Note, 15.

Cunha, F. and Heckman, J. J. (2008). Formulating, identifying and estimating the technology of cognitive and noncognitive skill formation. Journal of Human Resources, 43(4):738-782.

Cunha, F., Heckman, J. J., and Schennach, S. M. (2010). Estimating the technology of cognitive and noncognitive skill formation. Econometrica, 78(3):883-931.

Das, J., Dercon, S., Habyarimana, J., Krishnan, P., Muralidharan, K., and Sundararaman, V. (2013). School Inputs, Household Substitution, and Test Scores. American Economic Journal: Applied Economics, 5(2):29-57. 
Das, J. and Zajonc, T. (2010). India shining and Bharat drowning: Comparing two Indian states to the worldwide distribution in mathematics achievement. Journal of Development Economics, 92(2):175-187.

Deming, D., Hastings, J., Kane, T., and Staiger, D. (forthcoming). School choice, school quality and academic achievement. The American Economic Review, forthcoming.

Desai, S., Dubey, A., Vanneman, R., and Banerji, R. (2008). Private Schooling in india: A New Educational Landscape. In India Policy Forum, volume 5, pages 1-58. Global Economy and Development Program, The Brookings Institution.

Duflo, E., Dupas, P., and Kremer, M. (2012). School governance, teacher incentives, and pupil-teacher ratios: Experimental evidence from Kenyan primary schools. Working Paper 17939, National Bureau of Economic Research, Cambridge,MA.

Findley, M. J. and Cooper, H. M. (1983). Locus of control and academic achievement: A literature review. Journal of Personality and Social Psychology, 44(2):419.

Fiorini, M. and Keane, M. P. (2014). How the allocation of children's time affects cognitive and non-cognitive development. Journal of Labor Economics, 32(4):forthcoming.

French, R. J. and Kingdon, G. G. (2010). The relative effectiveness of private and government schools in rural India: Evidence from ASER data. Working Paper 10-03, Department of Quantitative Social Science,Institute of Education, London.

Glewwe, P. (1996). The relevance of standard estimates of rates of return to schooling for education policy: A critical assessment. Journal of Development Economics, $51(2): 267-290$.

Glewwe, P., Hanushek, E. A., Humpage, S., and Ravina, R. (2013). School resources and educational outcomes in developing countries: A review of the literature from 1990 to 2010. In Glewwe, P., editor, Education Policy in Developing Countries, chapter 2, pages 13-64. University of Chicago Press.

Glewwe, P. and Kremer, M. (2006). Schools, teachers, and education outcomes in developing countries. In Handbook of the Economics of Education, volume 2, pages 945-1017. Elsevier. 
Goldhaber, D. and Chaplin, D. (2012). Assessing the 'Rothstein Falsification Test': Does it really show teacher value-added models are biased? Working Paper 2011-5, Center for Education Data and Research, University of Washington.

Guarino, C., Reckase, M. D., and Wooldridge, J. M. (2012). Can value-added measures of teacher performance be trusted? IZA Discussion Papers 6602, Institute for the Study of Labor (IZA), Bonn.

Guarino, C., Reckase, M. D., and Wooldridge, J. M. (forthcoming). Can value-added measures of teacher performance be trusted? Education Finance and Policy.

Heady, C. (2003). The effect of child labor on learning achievement. World Development, 31(2):385-398.

Hsieh, C.-T. and Urquiola, M. (2006). The effects of generalized school choice on achievement and stratification: Evidence from chile's voucher program. Journal of Public Economics, 90(8):1477-1503.

Jacob, B. A., Lefgren, L., and Sims, D. P. (2010). The persistence of teacher-induced learning. Journal of Human Resources, 45(4):915-943.

James, Z. (2013). Young Lives School Survey India 2010/2011 Data User Guide. Data documentation, UK Data Archive Study Number 7478.

James, Z. and Woodhead, M. (2014). Choosing and changing schools in India across private and government sectors: Young Lives evidence from Andhra Pradesh. Oxford Review of Education, 40(1):73-90.

Jimenez, E., Lockheed, M. E., and Paqueo, V. (1991). The relative efficiency of private and public schools in developing countries. The World Bank Research Observer, 6(2):205-218.

Kane, T. J., McCaffrey, D. F., Miller, T., and Staiger, D. O. (2013). Have we identified effective teachers? Validating Measures of Effective Teaching using Random Assignment. Research Paper. MET Project. Technical report, Bill \& Melinda Gates Foundation.

Kane, T. J. and Staiger, D. O. (2008). Estimating Teacher Impacts on Student Achievement: An Experimental Evaluation. Working Paper 14607. 
Kingdon, G. (2010). The impact of the sixth pay commission on teacher salaries: assessing equity and efficiency effects. RECOUP working paper no. 29, University of Cambridge.

Kingdon, G. and Teal, F. (2010). Teacher unions, teacher pay and student performance in India: A pupil fixed effects approach. Journal of Development Economics, 91(2):278-288.

Kingdon, G. G. (1996). The Quality and Efficiency of Private and Public Education: A Case-Study of Urban India. Oxford Bulletin of Economics and Statistics, 58(1):57-82.

Kingdon, G. G. (2007). The progress of school education in India. Oxford Review of Economic Policy, 23(2):168-195.

Kingdon, G. G. and Teal, F. (2007). Does performance related pay for teachers improve student performance? some evidence from india. Economics of Education Review, 26(4):473-486.

Kinsler, J. (2012). Assessing Rothstein's critique of teacher value-added models. Quantitative Economics, 3(2):333-362.

Kremer, M., Brannen, C., and Glennerster, R. (2013). The challenge of education and learning in the developing world. Science, 340(6130):297-300.

Kumra, N. (2008). An Assessment of the Young Lives sampling approach in Andhra Pradesh, India. Young Lives Technical Note 2.

Maddux, J. E. and Gosselin, J. T. (2002). Self-efficacy. Handbook of positive psychology, pages 277-287.

McEwan, P. J. (2013). Improving learning in primary schools of developing countries: A meta-analysis of randomized experiments. unpublished.

Munshi, K. and Rosenzweig, M. R. (2006). Traditional Institutions Meet the Modern World: Caste, Gender, and Schooling Choice in a Globalizing Economy. The American Economic Review, 96(4):1225-1252.

Muralidharan, K. (2013). Priorities for Primary Education Policy in India's 12 th five-year plan. In NCAER-Brookings India Policy Forum, volume 2013. 
Muralidharan, K. and Kremer, M. (2008). Public and Private Schools in Rural India. In Chakrabarti, R. and Peterson, P. E., editors, School choice international: Exploring public-private partnerships. The MIT Press.

Muralidharan, K. and Sundararaman, V. (2013a). The Aggregate Effect of School Choice - Evidence from a two-stage experiment in India. Working Paper 19440, National Bureau of Economic Research, Cambridge,MA.

Muralidharan, K. and Sundararaman, V. (2013b). Contract Teachers: Experimental Evidence from India. Working Paper 19440, National Bureau of Economic Research, Cambridge,MA.

Neal, D. (2013). The consequences of using one assessment system to pursue two objectives. The Journal of Economic Education, 44(4):339-352.

Outes-Leon, I. and Dercon, S. (2008). Survey attrition and attrition bias in Young Lives. Young Lives Technical Note 5, Young Lives, University of Oxford.

Pal, S. (2010). Public infrastructure, location of private schools and primary school attainment in an emerging economy. Economics of Education Review, 29(5):783794.

Pratham (2013). Annual Status of Education Report 2012. Pratham, New Delhi.

Rothstein, J. (2010). Teacher quality in educational production: Tracking, decay, and student achievement. The Quarterly Journal of Economics, 125(1):175-214.

Singh, A. (2014). Test score gaps between private and government sector students at school entry age in india. Oxford Review of Education, 40(1):30-49.

Todd, P. E. and Wolpin, K. I. (2003). On the Specification and Estimation of the Production Function for Cognitive Achievement. The Economic Journal, 113(485):F3-F33.

Todd, P. E. and Wolpin, K. I. (2007). The production of cognitive achievement in children: Home, school, and racial test score gaps. Journal of Human Capital, 1(1):91-136.

Van der Linden, W. J. and Hambleton, R. K. (1997). Item response theory: Brief history, common models, and extensions. In Van der Linden, W. J. and Ham- 
bleton, R. K., editors, Handbook of Modern Item Response Theory, pages 1-28. Springer Verlag.

Woodhead, M., Ames, P., Vennam, U., Abebe, W., and Streuli, N. (2009). Equity and quality? Challenges for early childhood and primary education in Ethiopia, India and Peru. Working Paper 55, Bernard van Leer Foundation, The Hague. 
Figure 1: Timing of interviews in Young Lives

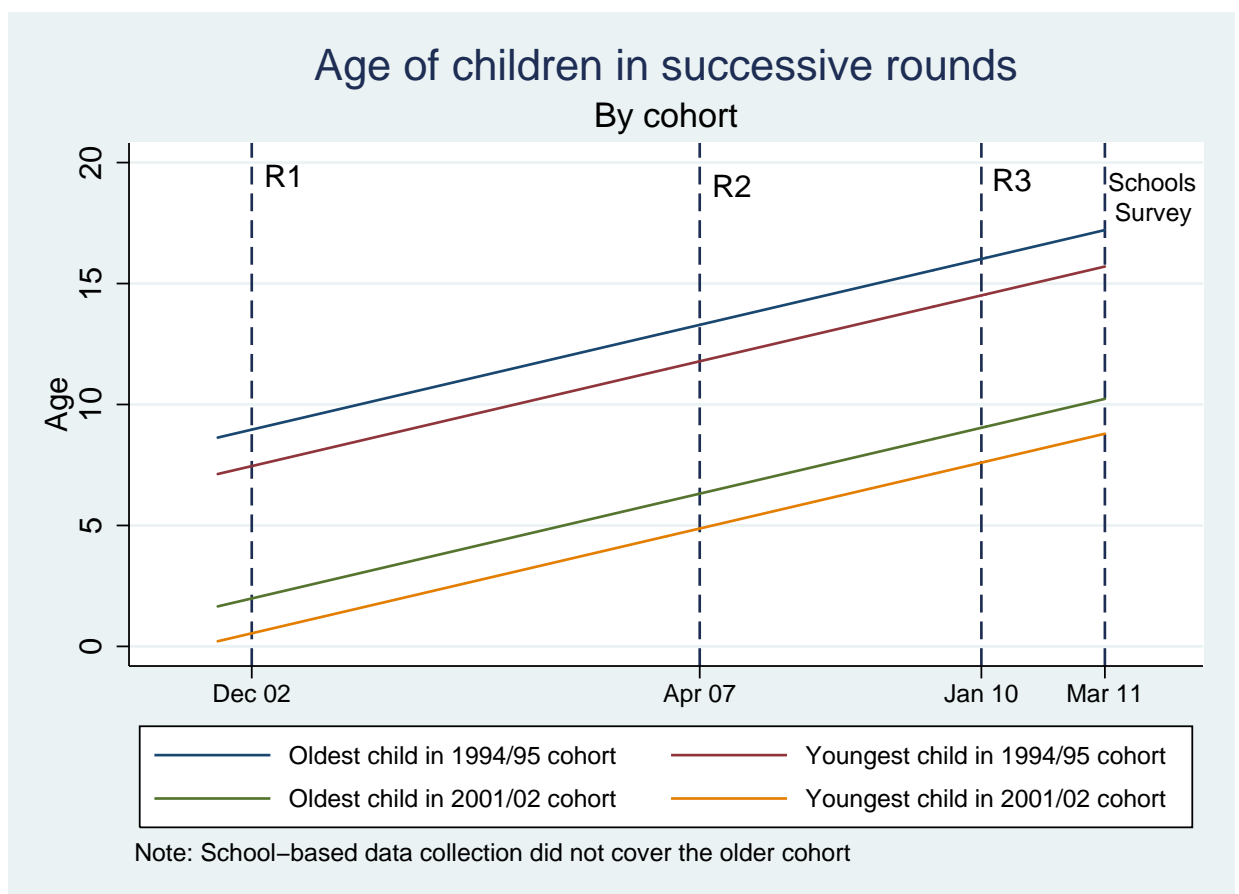


Table 1: Descriptive statistics - Younger Cohort, 8 years (2010)

\begin{tabular}{|c|c|c|c|c|c|c|}
\hline & \multicolumn{3}{|c|}{ Rural Areas } & \multicolumn{3}{|c|}{ Urban Areas } \\
\hline & Government & Private & Difference & Government & Private & Difference \\
\hline Mother's education (years) & 3.06 & 4.48 & $-1.42^{* * *}$ & 3.72 & 7.86 & $-4.13^{* * *}$ \\
\hline Father's Education (years) & 4.72 & 7.21 & $-2.49^{* * *}$ & 4.97 & 9.10 & $-4.13^{* * *}$ \\
\hline Male & 0.47 & 0.65 & $-0.18^{* * *}$ & 0.47 & 0.57 & -0.10 \\
\hline First-born child & 0.32 & 0.49 & $-0.16^{* * *}$ & 0.25 & 0.46 & $-0.21^{* * *}$ \\
\hline Scheduled Caste & 0.24 & 0.15 & $0.09 * * *$ & 0.21 & 0.08 & $0.13^{* *}$ \\
\hline Scheduled Tribe & 0.19 & 0.11 & $0.08^{* * *}$ & 0.07 & 0.01 & 0.06 \\
\hline Other Backward Classes & 0.49 & 0.49 & -0.00 & 0.39 & 0.47 & -0.07 \\
\hline Other castes & 0.09 & 0.25 & $-0.17 * * *$ & 0.33 & 0.44 & -0.11 \\
\hline Household size (2010) & 5.53 & 5.52 & 0.00 & 5.43 & 5.16 & 0.27 \\
\hline Monthly per capita expenditure (2006) & 622.80 & 931.58 & $-308.79^{* * *}$ & 699.15 & 1102.24 & $-403.09^{* * *}$ \\
\hline Monthly per capita expenditure (2010) & 900.77 & 1452.61 & $-551.83^{* * *}$ & 1102.00 & 1740.78 & $-638.78^{* * *}$ \\
\hline $\begin{array}{l}\text { Time use (hours spent on 'typical' day) } \\
\text { caring for others }\end{array}$ & 0.22 & 0.20 & 0.03 & 0.11 & 0.17 & -0.07 \\
\hline household chores & 0.40 & 0.27 & $0.13^{* * *}$ & 0.26 & 0.25 & 0.01 \\
\hline at school & 7.56 & 8.03 & $-0.47^{* * *}$ & 7.59 & 7.94 & $-0.35^{* *}$ \\
\hline studying after school & 1.76 & 2.01 & $-0.26 * * *$ & 1.63 & 1.96 & $-0.32 *$ \\
\hline unpaid work outside household & 0.02 & 0.00 & 0.01 & 0.00 & 0.00 & 0.00 \\
\hline paid work outside household & 0.01 & 0.00 & 0.00 & 0.01 & 0.00 & 0.01 \\
\hline play/general leisure & 4.85 & 4.32 & $0.53^{* * *}$ & 5.21 & 4.62 & $0.59^{* *}$ \\
\hline sleeping & 9.17 & 9.16 & 0.02 & 9.17 & 9.02 & 0.15 \\
\hline $\mathrm{N}$ & 956 & 476 & & 76 & 382 & \\
\hline
\end{tabular}

Cells present mean of variable within school type. Asterisks indicate significant difference between mean in private and government schools within urban and rural areas. ${ }^{* * *} \mathrm{p}<0.01$, $* * \mathrm{p}<0.05, * \mathrm{p}<0.1$ 


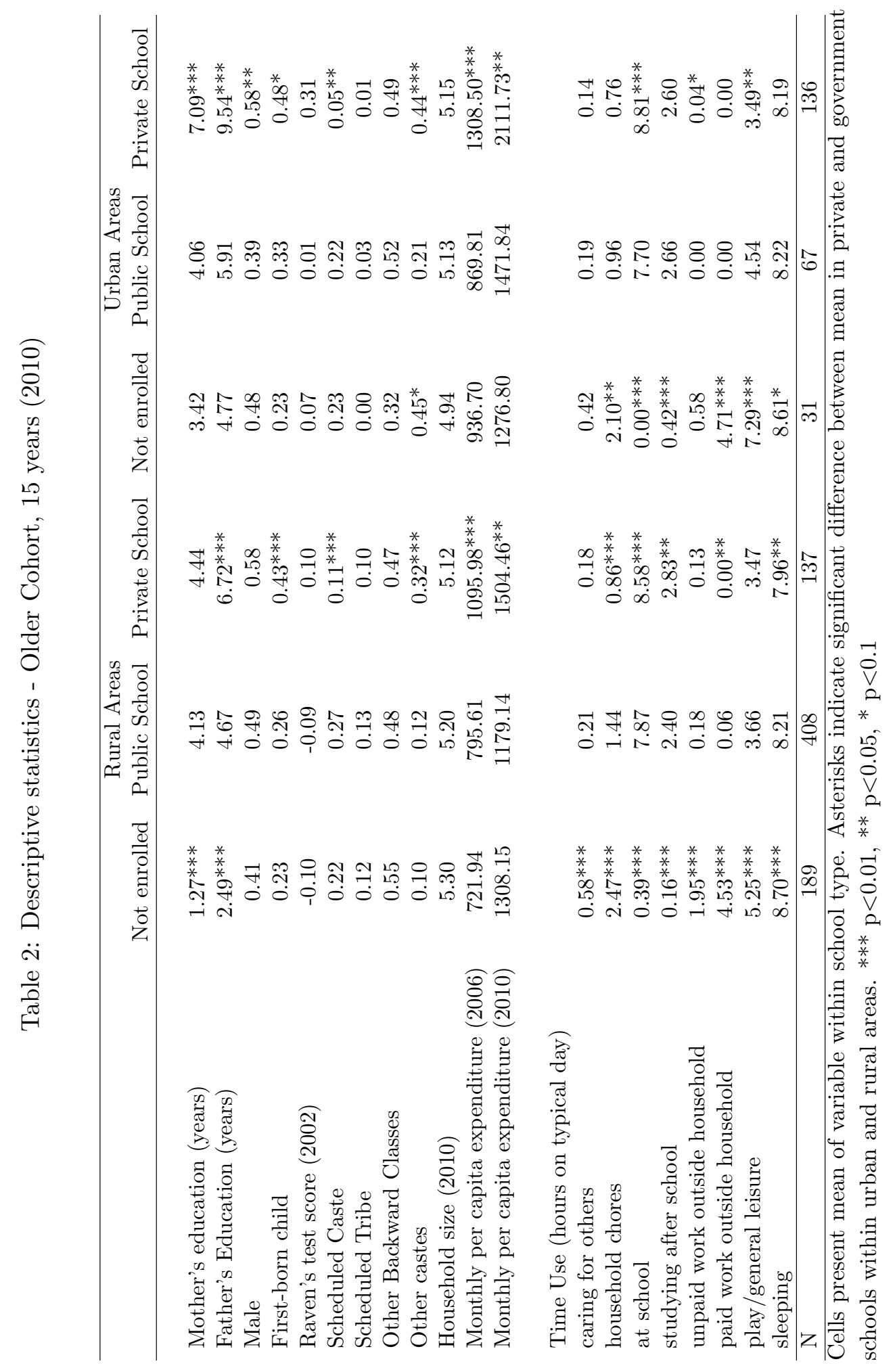


Table 3: Cross-sectional differences in test scores (Private - Government)

\begin{tabular}{lcccc}
\hline & Math & PPVT & Telugu & English \\
\hline Rural & & & & \\
8 years (Younger cohort, 2010) & $0.32^{* * *}$ & $0.36^{* * *}$ & & \\
9 years (Younger cohort, 2011) & $0.49^{* * *}$ & & $0.25^{* * *}$ & $1.05^{* * *}$ \\
15 years (Older cohort, 2010) & $0.49^{* * *}$ & $0.67^{* * *}$ & $0.45^{* * *}$ & \\
& & & & \\
Urban & & & & \\
8 years (Younger cohort, 2010) & $0.45^{* * *}$ & $0.25^{*}$ & & \\
15 years (Older cohort, 2011) & $0.34^{* * *}$ & $0.27^{* *}$ & 0.18 & \\
& & & & \\
& & & \\
\hline
\end{tabular}

Cells show cross-sectional mean difference in test scores. Asterisks indicate if difference is significantly different from zero $\left(* * * \mathrm{p}<0.01,{ }^{* *} \mathrm{p}<0.05,{ }^{*} \mathrm{p}<0.1\right)$.

Test scores are generated using Item Response Theory models and internally normalized (see Sec. 2.2). Only 23 children are in urban government schools in 9-year old sample. Results for this group are not reported. 
Table 4: Coefficient on Private School dummy

\begin{tabular}{|c|c|c|c|c|c|c|c|c|c|}
\hline & \multicolumn{9}{|c|}{ Rural Areas } \\
\hline & \multicolumn{4}{|c|}{ Without time use } & \multicolumn{3}{|c|}{ With time use } & \multirow[b]{2}{*}{ English } & \multirow[b]{2}{*}{$\mathrm{N}$} \\
\hline & Math & $\overline{\mathrm{PPVT}}$ & Telugu & English & Math & $\overline{\mathrm{PPVT}}$ & Telugu & & \\
\hline \multirow[t]{2}{*}{8 years $(\mathrm{YC}, 2010)$} & 0.018 & $0.17^{* * *}$ & & & - & $0.13^{* *}$ & & & 1,435 \\
\hline & $(0.064)$ & $(0.055)$ & & & $\begin{array}{l}0.063 \\
(0.059)\end{array}$ & $(0.061)$ & & & \\
\hline 9 years $(\mathrm{YC}, 2011)$ & $\begin{array}{l}0.091 \\
(0.056)\end{array}$ & & $\begin{array}{l}-0.18 \\
(0.10)\end{array}$ & $\begin{array}{l}0.73^{* * *} \\
(0.15)\end{array}$ & $\begin{array}{l}0.058 \\
(0.060)\end{array}$ & & $\begin{array}{c}-0.23^{* *} \\
(0.11)\end{array}$ & $\begin{array}{l}0.66^{* * *} \\
(0.14)\end{array}$ & 767 \\
\hline \multirow[t]{4}{*}{15 years $(\mathrm{OC}, 2010)$} & $\begin{array}{l}0.20^{* * *} \\
(0.065)\end{array}$ & $\begin{array}{c}0.18^{*} \\
(0.085)\end{array}$ & $\begin{array}{c}0.10 \\
(0.074)\end{array}$ & & $\begin{array}{l}0.20^{* *} \\
(0.075)\end{array}$ & $\begin{array}{c}0.16^{*} \\
(0.088)\end{array}$ & $\begin{array}{c}0.14 \\
(0.080)\end{array}$ & & 729 \\
\hline & \multicolumn{9}{|c|}{ Urban Areas } \\
\hline & \multicolumn{4}{|c|}{ Without time use } & \multicolumn{3}{|c|}{ With time use } & \multirow[b]{2}{*}{ English } & \multirow[b]{2}{*}{$\mathrm{N}$} \\
\hline & Math & $\overline{\mathrm{PPVT}}$ & Telugu & English & Math & $\overline{\mathrm{PPVT}}$ & $\overline{\text { Telugu }}$ & & \\
\hline 8 years $(Y C, 2010)$ & 0.030 & 0.058 & & & - & 0.084 & & & 458 \\
\hline & $(0.15)$ & $(0.24)$ & & & $\begin{array}{l}0.028 \\
(0.16)\end{array}$ & $(0.21)$ & & & \\
\hline 15 years $(\mathrm{OC}, 2010)$ & $\begin{array}{c}0.10 \\
(0.14)\end{array}$ & $\begin{array}{l}-0.019 \\
(0.050)\end{array}$ & $\begin{array}{c}-0.023 \\
(0.21)\end{array}$ & & $\begin{array}{l}0.092 \\
(0.11)\end{array}$ & $\begin{array}{l}-0.062 \\
(0.065)\end{array}$ & $\begin{array}{l}-0.11 \\
(0.19)\end{array}$ & & 233 \\
\hline
\end{tabular}

$\mathrm{YC}=$ Younger cohort, $\mathrm{OC}=$ Older cohort; ${ }^{* * *} \mathrm{p}<0.01,{ }^{* *} \mathrm{p}<0.05,{ }^{*} \mathrm{p}<0.1$

Cells correspond to the coefficient on the Private school dummy with government schools as the base category. Regressions control for child and household characteristics, sub-district fixed effects, lagged achievement score (Eqs. 6 and 7). See Sec 3.2 for details. Coefficients of other variables, and more parsimonious specifications (Eq:4-6) are presented on Appendixes A.1 to A.3 for rural areas. Standard errors, in parentheses, are clustered at sub-district (mandal level). $\mathrm{N}$ refers to number of observations in the regression on math test scores. 
Table 5: Heterogeneity by medium of instruction - Rural Areas, 9 years

\begin{tabular}{|c|c|c|c|c|c|c|}
\hline & \multicolumn{3}{|c|}{ Without time use } & \multicolumn{3}{|c|}{ With time use } \\
\hline & Math & Telugu & English & Math & Telugu & English \\
\hline Private School - English medium & $\begin{array}{c}-0.053 \\
(0.085)\end{array}$ & $\begin{array}{c}-0.35 * * \\
(0.15)\end{array}$ & $\begin{array}{c}0.83^{* * *} \\
(0.14)\end{array}$ & $\begin{array}{l}-0.095 \\
(0.079)\end{array}$ & $\begin{array}{c}-0.39 * * \\
(0.15)\end{array}$ & $\begin{array}{c}0.77^{* * * *} \\
(0.13)\end{array}$ \\
\hline Private school - Telugu medium & $\begin{array}{c}0.24^{*} \\
(0.13)\end{array}$ & $\begin{array}{r}-0.032 \\
(0.12)\end{array}$ & $\begin{array}{c}0.64^{* * *} \\
(0.15)\end{array}$ & $\begin{array}{c}0.22 \\
(0.13)\end{array}$ & $\begin{array}{c}-0.090 \\
(0.11)\end{array}$ & $\begin{array}{c}0.55^{* * *} \\
(0.15)\end{array}$ \\
\hline F-statistic (equality of coefficients) & 3.26 & 5.60 & 3.65 & 4.03 & 5.46 & 4.43 \\
\hline Prob $>F$ & 0.092 & 0.033 & 0.077 & 0.064 & 0.035 & 0.054 \\
\hline Observations & 766 & 708 & 670 & 766 & 708 & 670 \\
\hline
\end{tabular}

Cells correspond to the coefficient on the dummy variables for type of private school with government schools as the base category. Regressions control for child and household characteristics, sub-district fixed effects, lagged achievement score (Eq:7). See Sec 3.2 for details. Standard errors, in parentheses, are clustered at sub-district (mandal level). ${ }^{* * *} \mathrm{p}<0.01,{ }^{* *}$ $\mathrm{p}<0.05,{ }^{*} \mathrm{p}<0.1$

Table 6: Performance on specific English tasks

\begin{tabular}{lccccccc}
\hline VARIABLES & $\begin{array}{c}(1) \\
\text { Match } \\
\text { number } \\
\text { to word }\end{array}$ & $\begin{array}{c}\text { Match } \\
\text { picture } \\
\text { to word }\end{array}$ & $\begin{array}{c}\text { Match } \\
\text { sentence } \\
\text { to word }\end{array}$ & $\begin{array}{c}(4) \\
\text { Complete } \\
\text { sentence } \\
(\mathrm{MCQ})\end{array}$ & $\begin{array}{c}(5) \\
\text { Paragraph } \\
\text { comprehension } \\
\text { questions }\end{array}$ & $\begin{array}{c}(6) \\
\text { Complete } \\
\text { sentence } \\
\text { (open-ended) }\end{array}$ & $\begin{array}{c}(7) \\
\text { Write } \\
\text { sentence } \\
\text { description }\end{array}$ \\
\hline Private School & $0.25^{* * *}$ & $0.26^{* * *}$ & $0.18^{* * *}$ & $0.082^{* *}$ & $0.067^{* *}$ & $0.038^{* *}$ & $0.15^{* * *}$ \\
& $(0.069)$ & $(0.064)$ & $(0.045)$ & $(0.032)$ & $(0.026)$ & $(0.016)$ & $(0.029)$ \\
Govt. school mean & 0.63 & 0.68 & 0.56 & 0.39 & 0.23 & 0.02 & 0.03 \\
$\begin{array}{l}\text { Observations } \\
\text { R-squared }\end{array}$ & 670 & 670 & 670 & 670 & 670 & 670 & 670 \\
& 0.316 & 0.313 & 0.210 & 0.238 & 0.186 & 0.571 & 0.330 \\
\hline
\end{tabular}

Cells correspond to the coefficient on the Private school dummy with government schools as the base category. Regressions control for child and household characteristics, sub-district fixed effects, lagged achievement score (Eq:7). See Sec 3.2 for details. Standard errors, in parentheses, are clustered at sub-district (mandal level). ${ }^{* * *} \mathrm{p}<0.01,{ }^{* *} \mathrm{p}<0.05,{ }^{*} \mathrm{p}<0.1$ 
Table 7: Assessing bias due to omitted ability

\begin{tabular}{|c|c|c|c|c|c|c|c|c|}
\hline \multirow[b]{3}{*}{ VARIABLES } & (1) & $(2)$ & (3) & (4) & $(5)$ & (6) & (7) & $(8)$ \\
\hline & \multicolumn{3}{|c|}{ Test scores $(2009 / 10)$} & \multirow{2}{*}{\multicolumn{3}{|c|}{$\begin{array}{c}\text { Private school } \\
(2009 / 10)\end{array}$}} & \multicolumn{2}{|c|}{ Test scores $(2006 / 7$} \\
\hline & Math & PPVT & Telugu & & & & Math & PPVT \\
\hline Private school & $\begin{array}{l}0.19^{* *} \\
(0.075)\end{array}$ & $\begin{array}{c}0.15 \\
(0.086)\end{array}$ & $\begin{array}{c}0.13 \\
(0.076)\end{array}$ & & & & & \\
\hline Raven's score (2002) & $\begin{array}{c}0.084^{* * *} \\
(0.025)\end{array}$ & $\begin{array}{l}0.11^{* *} \\
(0.048)\end{array}$ & $\begin{array}{c}0.082^{* * *} \\
(0.022)\end{array}$ & $\begin{array}{c}0.060^{* *} \\
(0.022)\end{array}$ & $\begin{array}{c}0.016 \\
(0.018)\end{array}$ & $\begin{array}{c}0.010 \\
(0.020)\end{array}$ & $\begin{array}{c}0.12^{* * *} \\
(0.035)\end{array}$ & $\begin{array}{c}0.15^{* * *} \\
(0.035)\end{array}$ \\
\hline Math score (2007) & $\begin{array}{c}0.42^{* * *} \\
(0.048)\end{array}$ & & & & $\begin{array}{l}0.037^{*} \\
(0.020)\end{array}$ & & & \\
\hline PPVT score (2007) & & $\begin{array}{r}0.64^{* * *} \\
(0.067)\end{array}$ & $\begin{array}{c}0.48^{* * *} \\
(0.062)\end{array}$ & & & $\begin{array}{r}0.077^{* *} \\
(0.027)\end{array}$ & & \\
\hline Controls & $\mathrm{Y}$ & $\mathrm{Y}$ & $\mathrm{Y}$ & & $\mathrm{Y}$ & $\mathrm{Y}$ & Y & $\mathrm{Y}$ \\
\hline Time use & $\mathrm{Y}$ & $\mathrm{Y}$ & Y & & $\mathrm{Y}$ & $\mathrm{Y}$ & Y & $\mathrm{Y}$ \\
\hline Site fixed effects & $\mathrm{Y}$ & Y & $\mathrm{Y}$ & Y & Y & $\mathrm{Y}$ & $\mathrm{Y}$ & Y \\
\hline Observations & 729 & 715 & 706 & 545 & 544 & 544 & 729 & 728 \\
\hline R-squared & 0.549 & 0.639 & 0.519 & 0.122 & 0.293 & 0.303 & 0.338 & 0.468 \\
\hline
\end{tabular}

Columns 1-3 regress test scores on full set of covariates and the Raven's test score; coefficients on private school should be compared to Table 4. Columns 4-6 investigate partial correlations between the Raven's test and private schooling, for children in school in 2009/10, with increasing sets of controls. Columns 7-8 investigate partial correlations between lagged test scores (from 2006/7) and the Raven's test. Controls are defined as in main regression specification (Sec. 3.3). Standard errors are clustered at the site level. 


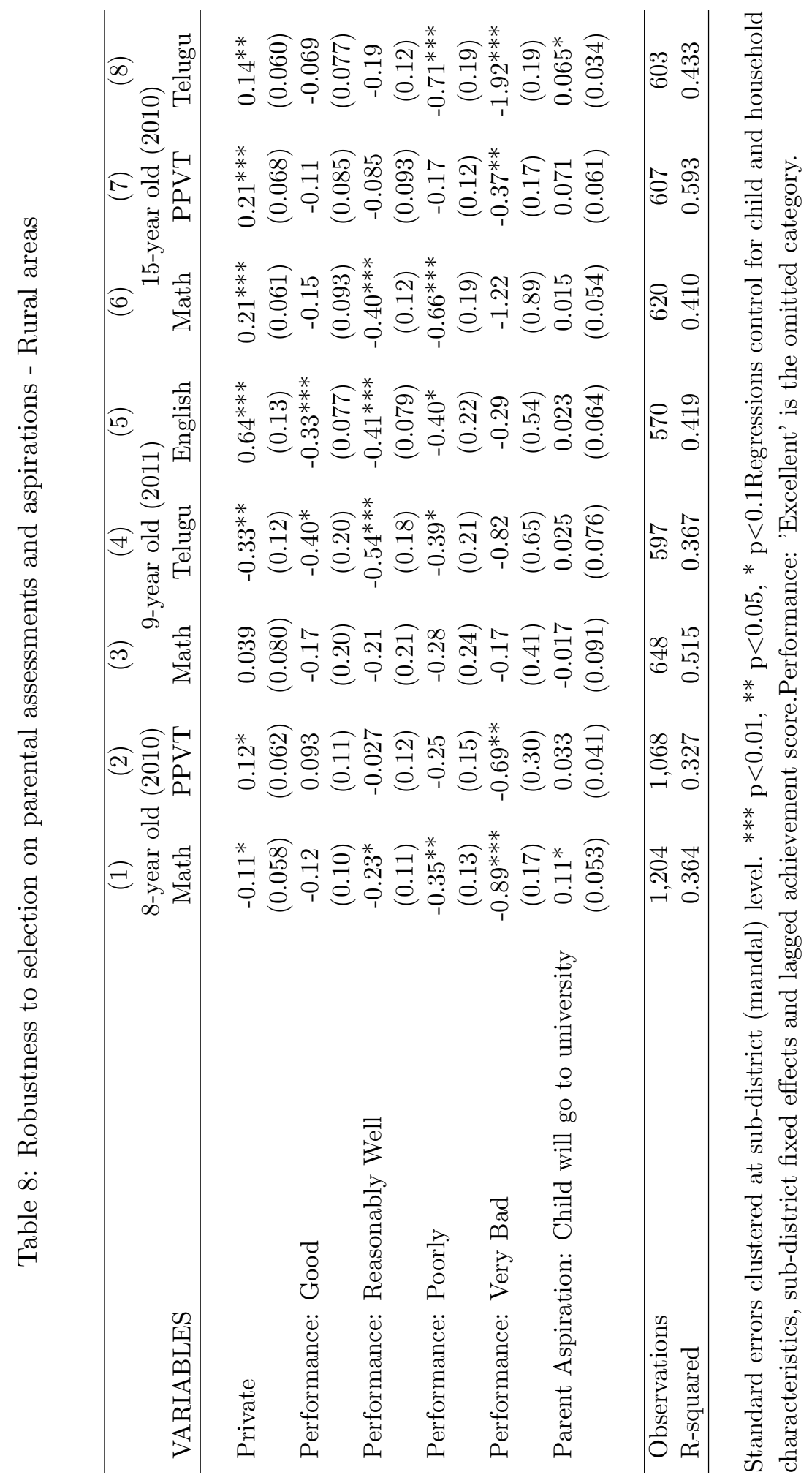


Table 9: Years spent in private and government schools between 2007/8 and 2009/10 academic years (inclusive)

\begin{tabular}{|c|c|c|c|c|c|c|c|c|c|c|c|c|c|}
\hline \multicolumn{14}{|c|}{8 years old } \\
\hline \multicolumn{9}{|c|}{ Rural areas } & \multicolumn{5}{|c|}{ Urban areas } \\
\hline \multicolumn{9}{|c|}{ Years in private schools } & \multicolumn{5}{|c|}{ Years in private schools } \\
\hline & & 0 & 1 & 2 & 3 & Total & & & 0 & 1 & 2 & 3 & Tota \\
\hline Years & 0 & 0 & 11 & 38 & 332 & 381 & Years & 0 & 0 & 0 & 4 & 369 & 373 \\
\hline in & 1 & 49 & 9 & 60 & 0 & 118 & in & 1 & 3 & 2 & 4 & 0 & 9 \\
\hline govt. & 2 & 180 & 51 & 0 & 0 & 231 & govt. & 2 & 15 & 11 & 0 & 0 & 26 \\
\hline \multirow[t]{2}{*}{ schools } & 3 & 702 & 0 & 0 & 0 & 702 & schools & 3 & 50 & 0 & 0 & 0 & 50 \\
\hline & Total & 933 & 71 & 98 & 332 & 1,434 & & Total & 68 & 13 & 8 & 369 & 458 \\
\hline
\end{tabular}

15 years old

\begin{tabular}{|c|c|c|c|c|c|c|c|c|c|c|c|c|c|}
\hline & & & & ral & reas & & & & & $\mathrm{Ur}$ & bar & are & \\
\hline & & & rs ir & pri & te sc & ools & & & & rs in & pr & vate & hools \\
\hline & & 0 & 1 & 2 & 3 & Total & & & 0 & 1 & 2 & 3 & Total \\
\hline Years & 0 & 114 & 4 & 7 & 97 & 222 & Years & 0 & 16 & 3 & 4 & 131 & 154 \\
\hline in & 1 & 17 & 2 & 22 & 0 & 41 & in & 1 & 3 & 1 & 3 & 0 & 7 \\
\hline govt. & 2 & 48 & 29 & 0 & 0 & 77 & govt. & 2 & 5 & 7 & 0 & 0 & 12 \\
\hline schools & 3 & 391 & 0 & 0 & 0 & 391 & schools & 3 & 61 & 0 & 0 & 0 & 61 \\
\hline & Total & 570 & 35 & 29 & 97 & 731 & & Total & 85 & 11 & 7 & 131 & 234 \\
\hline
\end{tabular}

This table is based on retrospective schooling histories collected in 2009/10. Years spent in kindergarten classes in private school are added to years of private schooling. 
Table 10: Estimating differential effectiveness of a year of schooling in private vs. government schools

(a) 8-year old

\begin{tabular}{lccccccccc}
\hline & \multicolumn{4}{c}{ Rural } & \multicolumn{4}{c}{ Urban } \\
VARIABLES & \multicolumn{3}{c}{ Without time use } & \multicolumn{2}{c}{ With time use } & \multicolumn{2}{c}{ Without time use } & \multicolumn{2}{c}{ With time use } \\
Math & PPVT & Math & PPVT & Math & PPVT & Math & PPVT \\
\hline \multirow{3}{*}{ Years in Public schools } & $0.62^{* * *}$ & $0.23^{* * *}$ & $0.60^{* * *}$ & $0.22^{* * *}$ & $0.65^{* *}$ & $0.30^{* *}$ & $0.63^{* *}$ & $0.26^{*}$ \\
after 2006/7 & $(0.072)$ & $(0.035)$ & $(0.073)$ & $(0.033)$ & $(0.21)$ & $(0.10)$ & $(0.21)$ & $(0.12)$ \\
Years in Private schools & $0.59^{* * *}$ & $0.30^{* * *}$ & $0.54^{* * *}$ & $0.28^{* * *}$ & $0.62^{* *}$ & $0.29^{*}$ & $0.59^{*}$ & 0.26 \\
after 2006/7 & $(0.079)$ & $(0.030)$ & $(0.076)$ & $(0.031)$ & $(0.21)$ & $(0.12)$ & $(0.22)$ & $(0.12)$ \\
& & & & & & & & \\
\hline Observations & 1,431 & 1,270 & 1,431 & 1,270 & 458 & 273 & 458 & 273 \\
R-squared & 0.405 & 0.326 & 0.429 & 0.337 & 0.357 & 0.219 & 0.374 & 0.258 \\
F statistic: Equal effect & 1.84 & 9.80 & 8.36 & 5.86 & 0.45 & 0.029 & 0.69 & 0.0097 \\
Prob >F & 0.20 & 0.0074 & 0.012 & 0.030 & 0.54 & 0.87 & 0.45 & 0.93 \\
\hline
\end{tabular}

(b) 15-year olds

\begin{tabular}{|c|c|c|c|c|c|c|c|c|c|c|c|c|}
\hline \multirow[b]{3}{*}{ VARIABLES } & \multicolumn{6}{|c|}{ Rural } & \multicolumn{6}{|c|}{ Urban } \\
\hline & \multicolumn{3}{|c|}{ Without time use } & \multicolumn{3}{|c|}{ With time use } & \multicolumn{3}{|c|}{ Without time use } & \multicolumn{3}{|c|}{ With time use } \\
\hline & Math & PPVT & Telugu & Math & PPVT & Telugu & Math & PPVT & Telugu & Math & PPVT & Telugu \\
\hline $\begin{array}{l}\text { Years in Public schools } \\
\text { after } 2006 / 7\end{array}$ & $\begin{array}{c}0.38^{* * *} \\
(0.043)\end{array}$ & $\begin{array}{c}0.18^{* * *} \\
(0.021)\end{array}$ & $\begin{array}{r}0.42^{* * *} \\
(0.028)\end{array}$ & $\begin{array}{r}0.41^{* * *} \\
(0.070)\end{array}$ & $\begin{array}{r}0.16^{* * *} \\
(0.050)\end{array}$ & $\begin{array}{r}0.42^{* * *} \\
(0.084)\end{array}$ & $\begin{array}{c}0.37^{* * *} \\
(0.052)\end{array}$ & $\begin{array}{c}0.20^{*} \\
(0.081)\end{array}$ & $\begin{array}{c}0.37 \\
(0.18)\end{array}$ & $\begin{array}{l}0.25^{*} \\
(0.11)\end{array}$ & $\begin{array}{c}0.13 \\
(0.13)\end{array}$ & $\begin{array}{c}0.16 \\
(0.14)\end{array}$ \\
\hline $\begin{array}{l}\text { Years in Private schools } \\
\text { after } 2006 / 7\end{array}$ & $\begin{array}{r}0.46^{* * *} \\
(0.048)\end{array}$ & $\begin{array}{c}0.24^{* * *} \\
(0.038)\end{array}$ & $\begin{array}{r}0.47^{* * *} \\
(0.035)\end{array}$ & $\begin{array}{c}0.49^{* * *} \\
(0.077)\end{array}$ & $\begin{array}{r}0.21^{* * *} \\
(0.046)\end{array}$ & $\begin{array}{r}0.48^{* * *} \\
(0.086)\end{array}$ & $\begin{array}{c}0.39 * * * \\
(0.065)\end{array}$ & $\begin{array}{c}0.18^{*} \\
(0.075)\end{array}$ & $\begin{array}{c}0.35^{* *} \\
(0.12)\end{array}$ & $\begin{array}{l}0.29^{* *} \\
(0.084)\end{array}$ & $\begin{array}{c}0.12 \\
(0.14)\end{array}$ & $\begin{array}{c}0.11 \\
(0.12)\end{array}$ \\
\hline Observations & 729 & 715 & 706 & 729 & 715 & 706 & 233 & 162 & 136 & 233 & 162 & 136 \\
\hline R-squared & 0.571 & 0.629 & 0.539 & 0.579 & 0.635 & 0.553 & 0.515 & 0.501 & 0.382 & 0.533 & 0.512 & 0.426 \\
\hline F statistic: Equal effect & 15.2 & 3.68 & 4.92 & 12.5 & 2.95 & 6.59 & 0.45 & 0.33 & 0.050 & 0.60 & 0.25 & 0.46 \\
\hline Prob $>F$ & 0.0016 & 0.076 & 0.044 & 0.0033 & 0.11 & 0.022 & 0.54 & 0.60 & 0.83 & 0.48 & 0.64 & 0.53 \\
\hline
\end{tabular}

This table is based on retrospective schooling histories collected in 2009/10. Years spent in kindergarten classes in private school are added to years of private schooling. 
Table 11: Statements and aggregate indexes of locus of control and self-efficacy

\begin{tabular}{lccc}
\hline & Government & Private & Difference \\
\hline & & & \\
Panel A. Individual statements & & & \\
Agency/Locus of control & 0.76 & 0.82 & $-0.06^{*}$ \\
I can do well in school if I work hard & 0.68 & 0.71 & -0.04 \\
I cannot do well in school, even if I try hard (-) & 0.75 & 0.71 & 0.04 \\
Making an extra effort rarely leads to success (-) & 0.71 & 0.74 & -0.03 \\
Going to school is of no use to me (-) & & & \\
& & & \\
Self-efficacy & 0.71 & 0.80 & $-0.10^{* *}$ \\
I am really good at learning English & 0.52 & 0.70 & $-0.17^{* * *}$ \\
Doing maths is very difficult for me (-) & 0.66 & 0.67 & -0.01 \\
I am proud of my achievements in school & 0.72 & 0.82 & $-0.11^{* *}$ \\
I can do my classwork at school without help & 0.56 & 0.64 & -0.08 \\
I am really good at learning Telugu & 0.79 & 0.85 & -0.05 \\
I am really good at learning maths & & & \\
& & & \\
Panel B. Aggregated indexes & -0.08 & 0.01 & -0.08 \\
Agency/locus of control index & -0.15 & 0.20 & $-0.35^{* * *}$ \\
Self-efficacy index & & & \\
& 559 & 207 & 766 \\
\hline
\end{tabular}

Negatively coded answers, indicated by (-) have been reversed in this table and in the generation of composite indexes. An affirmative response indicates a positive outcome for all statements as displayed in table above.Statements are aggregated into composite indexes by averaging across non-missing responses and normalizing to have a mean of zero and a standard deviation of 1.The table only includes children in rural areas covered in the 2011 school based data collection. ${ }^{* * *} \mathrm{p}<0.01,{ }^{* *} \mathrm{p}<0.05,{ }^{*} \mathrm{p}<0.1$ 
Table 12: The impact of private schooling on psychosocial skills - Rural areas, 9 years

\begin{tabular}{|c|c|c|c|c|c|c|}
\hline \multirow[b]{2}{*}{ VARIABLES } & (1) & $(2)$ & $(3)$ & (4) & $(5)$ & (6) \\
\hline & \multicolumn{3}{|c|}{ Agency/Locus-of-control index } & \multicolumn{3}{|c|}{ Self-efficacy index } \\
\hline \multirow[t]{2}{*}{ Private School } & 0.16 & 0.059 & 0.030 & $0.30 * * *$ & 0.099 & 0.049 \\
\hline & $(0.11)$ & $(0.15)$ & $(0.16)$ & $(0.070)$ & $(0.092)$ & $(0.099)$ \\
\hline \multirow[t]{2}{*}{ Mother's education level } & & 0.0062 & 0.0047 & & -0.0016 & -0.0060 \\
\hline & & $(0.0062)$ & $(0.0057)$ & & $(0.011)$ & $(0.0096)$ \\
\hline \multirow[t]{2}{*}{ Father's education level } & & 0.0076 & 0.0063 & & 0.0068 & 0.0055 \\
\hline & & $(0.0063)$ & $(0.0065)$ & & $(0.0068)$ & $(0.0068)$ \\
\hline \multirow[t]{2}{*}{ Male } & & 0.019 & 0.028 & & $0.14^{*}$ & $0.14^{*}$ \\
\hline & & $(0.088)$ & $(0.087)$ & & $(0.070)$ & $(0.071)$ \\
\hline \multirow[t]{2}{*}{ Eldest child } & & $0.12^{*}$ & 0.11 & & 0.079 & 0.050 \\
\hline & & $(0.062)$ & $(0.063)$ & & $(0.10)$ & $(0.11)$ \\
\hline \multirow[t]{2}{*}{ Scheduled Castes } & & 0.014 & 0.015 & & -0.046 & -0.039 \\
\hline & & $(0.19)$ & $(0.20)$ & & $(0.12)$ & $(0.15)$ \\
\hline \multirow[t]{2}{*}{ Scheduled Tribes } & & 0.11 & 0.11 & & $-0.48^{* *}$ & $-0.55^{* *}$ \\
\hline & & $(0.15)$ & $(0.16)$ & & $(0.21)$ & $(0.23)$ \\
\hline \multirow[t]{2}{*}{ Other Backward Classes } & & -0.079 & -0.071 & & $-0.18^{* *}$ & -0.15 \\
\hline & & $(0.13)$ & $(0.13)$ & & $(0.080)$ & $(0.100)$ \\
\hline \multirow[t]{2}{*}{ Wealth index } & & 0.33 & 0.32 & & 0.77 & 0.60 \\
\hline & & $(0.25)$ & $(0.27)$ & & $(0.46)$ & $(0.48)$ \\
\hline \multirow[t]{2}{*}{ Household size } & & 0.00091 & 0.0026 & & $0.033^{* *}$ & $0.037^{* *}$ \\
\hline & & $(0.018)$ & $(0.019)$ & & $(0.012)$ & $(0.013)$ \\
\hline \multirow[t]{2}{*}{ CDA Quantitative score (2007) } & & & 0.072 & & & $0.12^{*}$ \\
\hline & & & $(0.043)$ & & & $(0.055)$ \\
\hline \multirow[t]{2}{*}{ PPVT score (2007) } & & & 0.012 & & & $0.11^{*}$ \\
\hline & & & $(0.039)$ & & & $(0.054)$ \\
\hline \multirow[t]{2}{*}{ Constant } & $-0.10^{* * *}$ & $-0.32^{*}$ & $-0.30^{*}$ & $-0.13^{* * *}$ & $-0.59^{* * *}$ & $-0.47^{* *}$ \\
\hline & $(0.029)$ & $(0.16)$ & $(0.16)$ & $(0.019)$ & $(0.18)$ & $(0.20)$ \\
\hline Observations & 766 & 766 & 752 & 766 & 766 & 752 \\
\hline R-squared & 0.146 & 0.160 & 0.162 & 0.098 & 0.140 & 0.169 \\
\hline
\end{tabular}

Standard errors, in parentheses, are clustered at sub-district level. ${ }^{* * *} \mathrm{p}<0.01,{ }^{* *}$ $\mathrm{p}<0.05,{ }^{*} \mathrm{p}<0.1$ Regression includes sub-district fixed effects. Results are from rural sample of the 2011 data collection, collected at the school. 


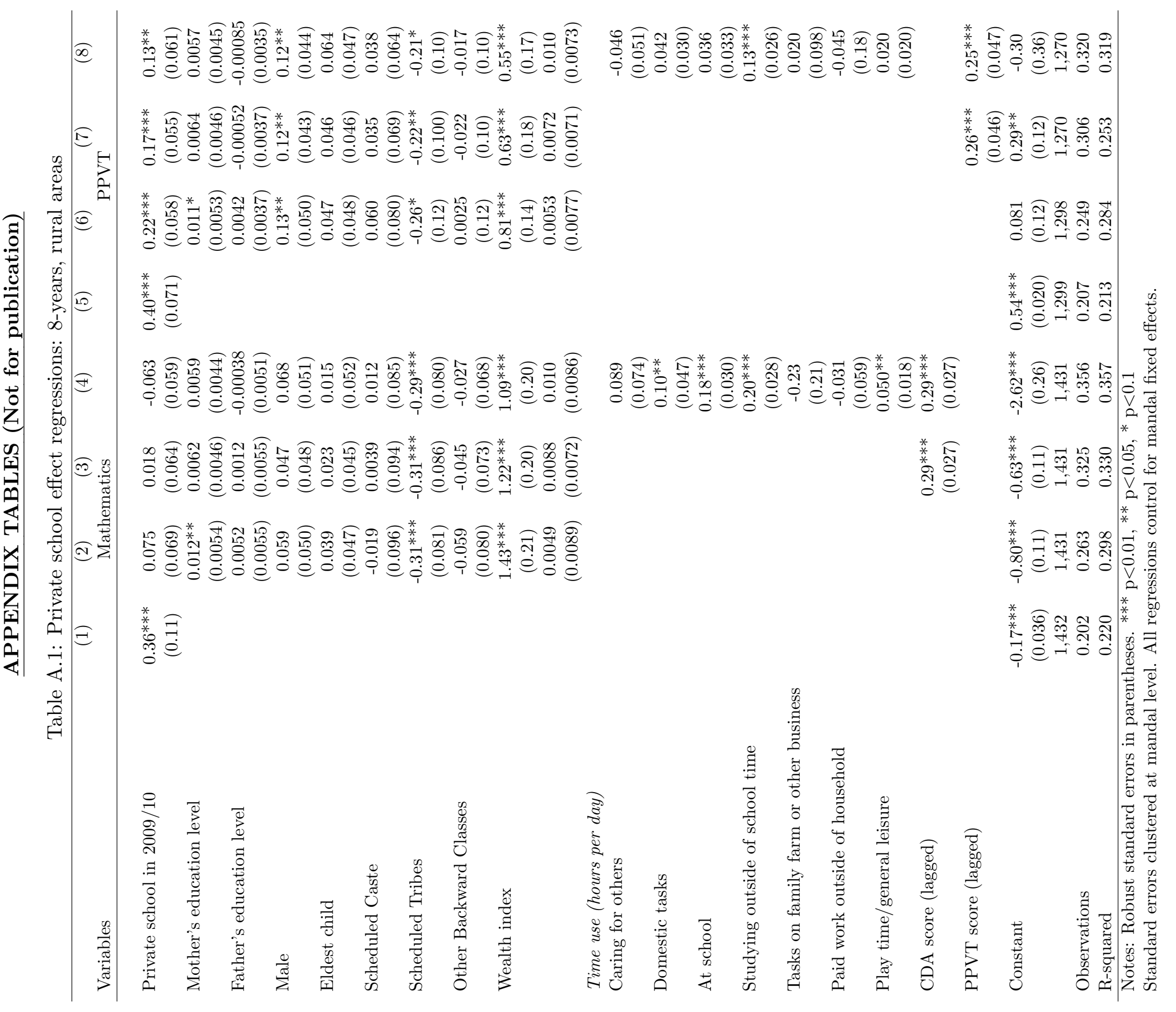




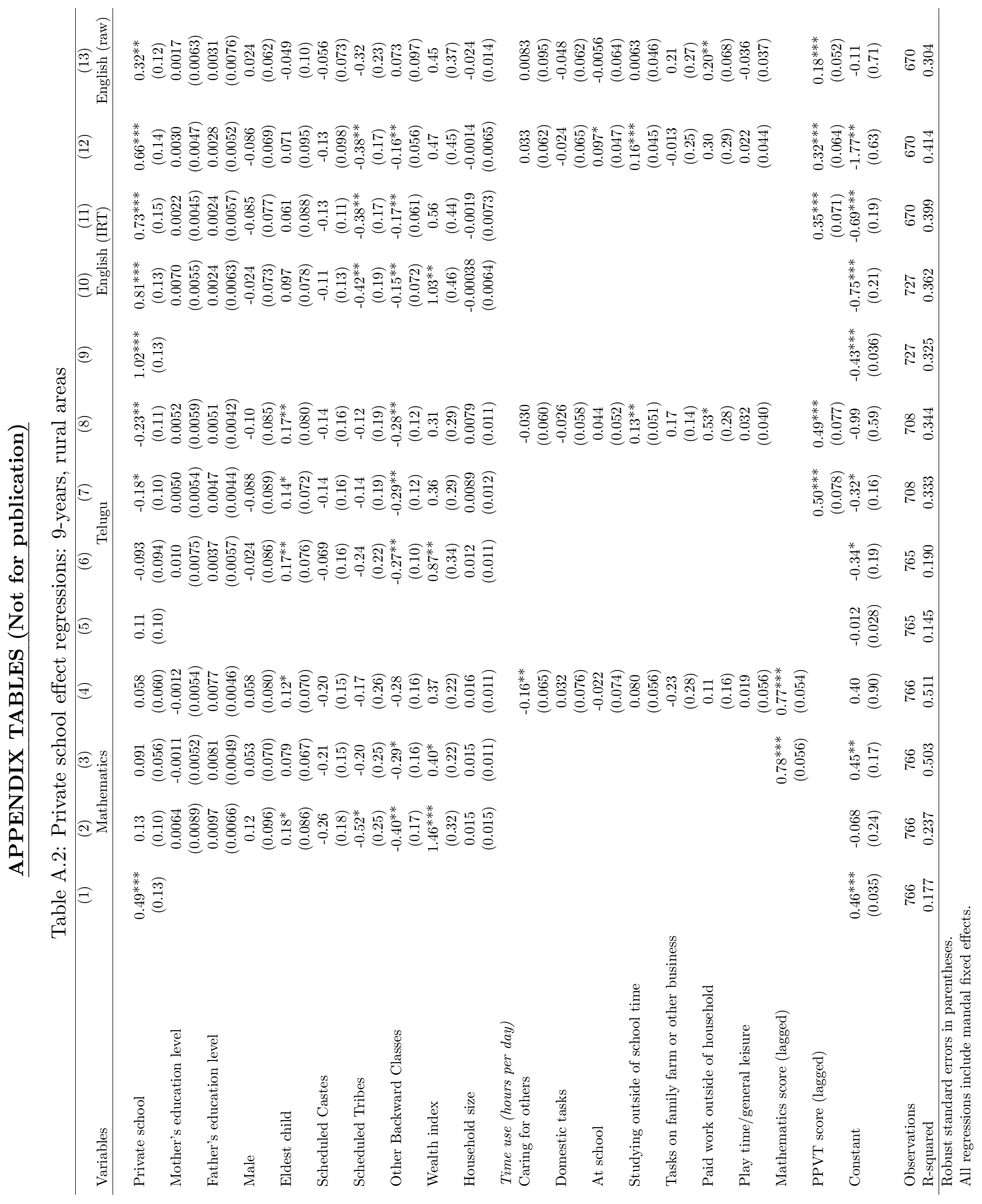




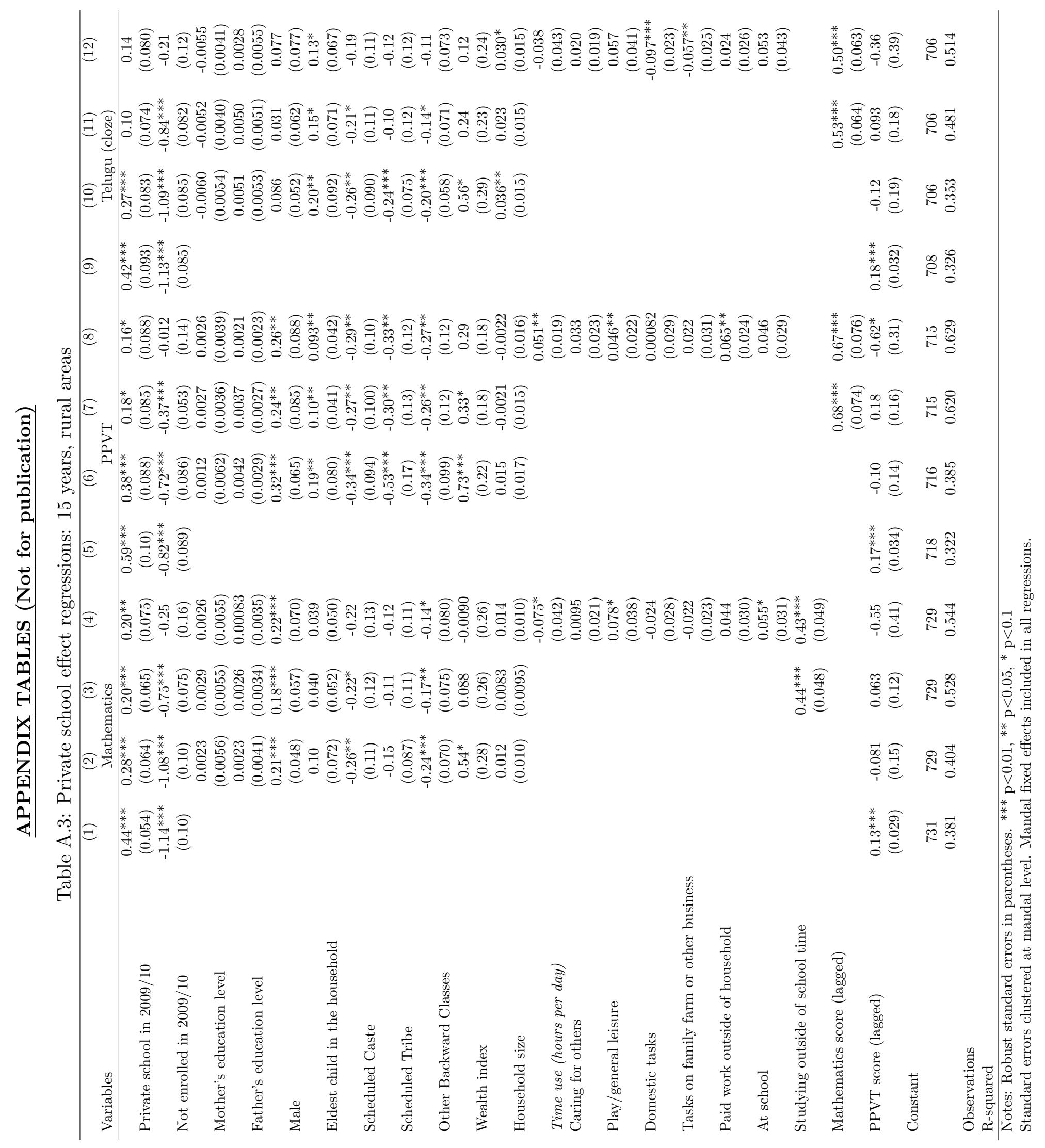




\section{APPENDIX TABLES (Not for publication)}

Table A.4: Restricting sample to non-migrants

\begin{tabular}{|c|c|c|c|c|c|}
\hline & Math & PPVT & Telugu & English & $\mathrm{N}$ \\
\hline 8 years (YC, 2010) & $\begin{array}{c}0.15 \\
(0.10)\end{array}$ & $\begin{array}{l}0.17^{* *} \\
(0.066)\end{array}$ & & & 888 \\
\hline \multirow[t]{3}{*}{15 years (OC, 2010) } & $\begin{array}{l}0.21^{* *} \\
(0.078)\end{array}$ & $\begin{array}{l}0.20^{*} \\
(0.11)\end{array}$ & $\begin{array}{l}0.18^{* *} \\
(0.079)\end{array}$ & & 601 \\
\hline & & \multicolumn{2}{|c|}{ With time use } & & \\
\hline & Math & $\overline{\mathrm{PPVT}}$ & $\overline{\text { Telugu }}$ & English & $\mathrm{N}$ \\
\hline 8 years $(\mathrm{YC}, 2010)$ & $\begin{array}{c}0.17 \\
(0.17)\end{array}$ & $\begin{array}{c}0.19 \\
(0.22)\end{array}$ & & & 458 \\
\hline 15 years (OC, 2010) & $\begin{array}{l}0.092 \\
(0.11)\end{array}$ & $\begin{array}{l}-0.062 \\
(0.065)\end{array}$ & $\begin{array}{l}-0.11 \\
(0.19)\end{array}$ & & 233 \\
\hline
\end{tabular}

$\mathrm{YC}=$ Younger cohort, $\mathrm{OC}=$ Older cohort; ${ }^{* * *} \mathrm{p}<0.01,{ }^{* *} \mathrm{p}<0.05,{ }^{*} \mathrm{p}<0.1$

Cells correspond to the coefficient on the Private school dummy with government schools as the base category. Regressions control for child and household characteristics, sub-district fixed effects, lagged achievement score (Eqs. 6 and 7). See Sec 3.2 for details. Coefficients of other variables, and more parsimonious specifications (Eq:4-6) are presented on Appendixes A.1 to A.3 for rural areas. Standard errors, in parentheses, are clustered at sub-district (mandal level). $\mathrm{N}$ refers to number of observations in the regression on math test scores. 